Federal Reserve Bank of Minneapolis

Research Department

\title{
Deposit Insurance: A Reconsideration
}

\author{
John H. Boyd, Chun Chang, \\ and Bruce D. Smith
}

Working Paper 593

December 1998

\begin{abstract}
This paper undertakes a simple general equilibrium analysis of the consequences of deposit insurance programs, the way in which they are priced and the way in which they fund revenue shortfalls. We show that the central issue is how the government will make up any FDIC losses. Under one scheme for making up the losses, we show that FDIC policy is irrelevant: it does not matter what premium is charged, nor does it matter how big FDIC losses are. Under another scheme, all that matters is the magnitude of the losses. And there is no presumption that small losses are "good." We also show that multiple equilibria can be observed and Pareto ranked. Some economies may be "trapped" in equilibria with inefficient financial systems. Our analysis provides counterexamples to the following propositions. (1) Actuarially fair pricing of deposit insurance is always desirable. (2) Implicit FDIC subsidization of banks through deposit insurance is always undesirable. (3) "Large" FDIC losses are necessarily symptomatic of a poorly designed deposit insurance system.

*Boyd, Federal Reserve Bank of Minneapolis and University of Minnesota; Chang, University of Minnesota; Smith, University of Texas-Austin and Federal Reserve Bank of Cleveland. The views expressed herein are those of the authors and not necessarily those of the Federal Reserve Bank of Minneapolis or the Federal Reserve System.
\end{abstract}




\section{Introduction}

Recent events in Asia and elsewhere ${ }^{1}$ have served to reemphasize the importance of deposit insurance programs and related government guarantees of the banking system. While the presence of such insurance and guarantees has probably averted open bank runs in a number of economies, the financial crises in Asia and in other parts of the world are stark illustrations of the moral hazard problems created by deposit insurance schemes. Nor are these problems associated with the presence of deposit insurance alone: when a government decides that some set of banks is "too big to fail," that obviously creates its own moral hazard problems. ${ }^{2}$

All of this raises the obvious issue of the appropriate design of deposit insurance systems. This issue is, of course, important in any number of countries. But it looms particularly large in many developing and transitional economies where the design of deposit insurance programs is currently underway or under active consideration.

No doubt the issue that has received the most attention in discussions of deposit insurance is the question of how it should be priced. ${ }^{3}$ Many have argued that it is important, for example, that deposit insurance be priced in an actuarially fair manner. ${ }^{4}$ If it is not, bank incentives are alleged to be distorted. Many have also argued that substantial subsidies to the banking system should be avoided. And, it is no doubt widely accepted that when government deposit insurance systems experience substantial losses, this is a signal that "something" is wrong with the system.

We revisit these issues in a model that brings the general equilibrium consequences of deposit insurance programs to the forefront. We consider a program where bank deposits are 100 percent insured, and where a flat rate deposit insurance premium is imposed on banks. ${ }^{5}$ Banks take insured deposits and make loans to agents who have a choice of two investment projects. Banks - and societygenerally care which projects are undertaken, and different projects imply different default risks on loans. Any borrower's project choice can be observed by a lender only by bearing a cost: this introduces a moral 
hazard problem associated with bank lending. In addition, project returns can be observed only at some cost by outsiders: this gives rise to a conventional costly state verification (CSV) problem in lending.

Therefore, our model of the banking firm allows for two forms of moral hazard: ex post moral hazard due to costly state verification, and ex ante moral hazard due to the possibility of inappropriate investment decisions by borrowers. The first problem is quite standard and should require no further explanation here. The second is somewhat less standard in the literature and merits some comment. We adopt a formulation where a misallocation of funds by borrowers allows them to engage in excess consumption of "perk.s." This moral hazard problem, if uncontrolled, results in a transfer of income from banks to firm owners, and it also allows firm owners to reallocate assets for their own personal consumption. Naturally this reallocation is associated with a distortion of firm investments that acts to the detriment of the firm's creditors. Indeed, it is also socially detrimental, since it would typically be better to allow firm owners to take income directly, rather than to take resources of the same value in the form of "in-kind" perks consumption. Our moral hazard problem therefore has two related dimensions: a misallocation of investment associated with a socially inefficient diversion of funds. Both types of moral hazard are often observed in practice, and we believe that this model captures both in a parsimonious way. ${ }^{6}$

In this context we allow banks to take various actions to address the problem of moral hazard. Which actions they take in turn affect the probability of bank failure. This aspect of the model gives rise to a moral hazard problem between banks and a (governmental) deposit insurer, as well as to the moral hazard problem already present between banks and borrowers.

In a partial equilibrium context, the pricing of deposit insurance does typically affect the incentives of banks to address problems of moral hazard in this model. Thus, if we were to confine our analysis to partial equilibrium reasoning, we would conclude that the pricing of deposit insurance should matter for the severity of moral hazard problems between banks and borrowers, and for the severity of moral hazard problems between banks and the FDIC. And, in our examples, we would conclude that pricing deposit insurance in an actuarially fair manner was often quite a good policy. 
However, when these issues are analyzed in a general equilibrium context, matters are substantially different. Indeed, we show that from the perspective of a general equilibrium, the single most important issue is the following: how are any shortfalls in FDIC revenue (FDIC losses) made up? To illustrate the relevance of this question we consider two possibilities, which superficially appear not to be very different. In the first, any FDIC shortfalls are made up by levying a lump-sum tax on all savers. In the second, FDIC shortfalls are recovered by levying a lump-sum tax on all savers, and on all (funded) borrowers. The results we then obtain are as follows.

When FDIC losses are covered by lump-sum taxation of savers alone, we find that all dimensions of government policy are irrelevant to any aspect of an equilibrium that matters from a welfare perspective. In particular, neither the choice of a deposit insurance premium, nor the magnitude of FDIC losses matters to any agent. It is also true that these choices do not affect the risk of either borrower or bank default, nor do they affect banks' incentives with respect to lending strategies. They, therefore, have no implications for the severity of the moral hazard problems that society confronts. In short, given that 100 percent deposit insurance is provided, it is totally irrelevant how the FDIC prices this insurance.

Why should this be the case? As we show, variations in FDIC policy parameters do affect real rates of interest on deposits. The higher is the deposit insurance premium, for example, the lower is the (real) rate of interest on deposits. Similarly, higher deposit insurance premia imply lower FDIC losses and lower lump-sum taxes. But these lower taxes/losses simply offset the consequences of lower rates of interest on deposits. There are no net welfare changes caused by varying deposit insurance premia. And, by implication, it is similarly irrelevant how large the FDIC's losses are.

When lump-sum taxes are levied on savers and (funded) borrowers, matters are somewhat different. Here what is important is the magnitude of FDIC (expected) losses, in discounted present value terms. When FDIC losses are below some critical level, banks will take one possible course of action to deal with moral hazard problems. When FDIC losses are above this level, they will take another. However, all that matters, economically speaking, is whether FDIC losses are below or above the critical level. Conditional on FDIC losses being below (or above) this level we have the same result as before: 
marginal changes in FDIC policy parameters have no implications for any equilibrium quantities that affect agents' welfare. And, this is for the same reason as before.

Under this second method for making up FDIC losses, the magnitude of these losses does generally matter (even though only in the way just described). Is it "good" for FDIC loss levels to be low? While we have no general results on this point, we do compute numerical examples where, in fact, low levels of FDIC losses are "bad" in the following sense. Equilibrium welfare levels of all agents could be improved if FDIC losses were increased so that they were above the critical level we mentioned. Thus, there is no general presumption in favor of low FDIC losses. Moreover, actuarially fair pricing of deposit insurance may well be a suboptimal policy, as it is in the example mentioned, because it leads FDIC losses to be low.

Our first main results then concern the potential irrelevance of FDIC policy choices and the fact that - if these have any relevance - it may be undesirable to have FDIC losses be too low. But we also have other results. These concern the potential for multiplicity of equilibria.

We describe conditions under which an economy may have two equilibria. These equilibria differ according to the way in which banks address problems of moral hazard. They also yield different rates of interest on loans and deposits, and they imply different rates of bank failure and (possibly) different loss levels for the FDIC. We also show that when two equilibria exist, they can often be Pareto ranked. Thus it is quite possible for an economy to end up in a Pareto inferior equilibrium.

This result has several possible interpretations. One is that the financial analogs of development traps are quite possible under this method of providing deposit insurance. In particular, two otherwise identical economies can end up in different equilibria, one of which is unambiguously preferred to the other. Thus some economies may have relatively inefficient banking systems for purely endogeneous reasons. And, as many have argued, ${ }^{7}$ this could generally be expected to translate into low levels of development as well. Moreover, when FDIC losses are recovered by taxing (funded) borrowers as well as savers, the potential for multiple equilibria may well depend on the policy choices made by the FDIC. We illustrate by example how this could occur. 
Another possible interpretation of this multiplicity of equilibria is as follows. Imagine a repeated version of our economy where in some (all) periods there are two (possibly Pareto ranked) equilibria. The economy transits randomly between these two equilibria in response to the realization of some "sunspot" variable. Then deposit insurance programs of the type we have described may be associated with endogenously generated (sunspot) volatility. And, under some methods of making up FDIC losses, FDIC policy choices may well affect the scope for such sunspot equilibria to arise. Thus, the FDIC could make choices which either allow cyclical "sunspot" variability to exist, or which prevent such variability from being observed. We again illustrate this possibility by example.

Finally, under this "business cycle" interpretation of our model, real shocks may interact with the deposit insurance program so that "sunspots" can be relevant only for certain realizations of real shocks. We present some examples which demonstrate how this can occur.

The remainder of the paper proceeds as follows. Section I describes the environment and the deposit insurance system. Section II undertakes a partial equilibrium analysis of bank behavior, while section III describes a full general equilibrium. Section IV gives some numerical examples, and section V concludes.

\section{The Model}

We consider a two-period model populated by a continuum of agents with unit mass. Agents fall into one of three categories: borrowers (or firms), bankers (or potential bankers), and depositors (savers). In addition, there is a government operated deposit insurance system (the FDIC). We now describe each set of agents.

\section{A. Firms}

Borrowers (firms) are a fraction $\alpha \in(0,1)$ of the population. All borrowers are endowed with two investment projects, although at most one of the projects can be operated. A project that is activated 
in the first period yields a random gross return of $z$ per unit invested, in period 2. For both projects $z \in$ $[0, \bar{z}]$.

Projects differ on two dimensions: their scale of operation, and their probability distributions of returns. Type 1 projects require $\mathrm{q}_{1}>1$ units of period one resources ("funds") to operate. We assume that all projects are indivisible, so that a type 1 project requires an investment of exactly $\mathrm{q}_{1}$ units. For a type 1 project that is operated at time 1 , the probability of receiving a return no greater than $\widetilde{z}$ is prob $(z$ $\leq \widetilde{z})=\mathrm{G}(\widetilde{z})$. Let $\mathrm{g}(z)$ denote the pdf of this distribution, and assume that $\mathrm{g}(z)>0 \forall z \in(0, \bar{z})$. We will often assume that $\mathrm{g}$ is (almost) everywhere differentiable, and we let $\hat{z}_{1}$ denote the expected gross return, per unit invested, if project 1 is operated. Project return realizations are independently and identically distributed across agents.

In order to operate project 2 , in contrast, a firm requires $\mathrm{q}_{2}$ units of first period funds, with $\mathrm{q}_{2} \in(1$, $\left.\mathrm{q}_{1}\right)$. These projects are again indivisible, and if project 2 is funded, prob $(z \leq \widetilde{z})=\mathrm{F}(\widetilde{z})$. Let $\mathrm{f}$ denote the pdf of this distribution, assume that $\mathrm{f}(z)>0 \forall z \in(0, \bar{z})$, and let $\hat{z}_{2}$ denote the expected gross return on investments in project 2 . As before, we will typically assume that $\mathrm{f}$ is (almost) everywhere differentiable, and we assume that project return realizations are iid across firms.

To fix ideas, we will assume that the probability distribution of returns on project 1 displays first order stochastic dominance over the distribution of returns on project 2 . Thus

(a.1) $\quad \mathrm{F}(z) \geq \mathrm{G}(z), \forall z$.

It follows that $\hat{z}_{1}>\hat{z}_{2}$. Thus, project 1 is, on average, more productive than project 2 (not inclusive of monitoring costs), but it requires more resources to operate.

As we indicated previously, a borrower could in principle operate either project 1 or project 2 . It is not possible to operate both projects, or convex combinations of both projects. Such assumptions are common in models with moral hazard and costly state verification.

Firms have no first or second period funds endowment. They therefore require external funding to operate an investment project. If no project is operated, we assume that borrowers can engage in some 
other activity that yields the exogenously given utility level $\bar{u}$. Firms (borrowers) are assumed to operate any project that yields an expected payoff of at least $\bar{u}$.

\section{Information}

The provision of external finance is subject to two potential informational asymmetries: a moral hazard problem and a costly state verification problem. In particular, a moral hazard problem arises because a borrower's choice of project is unobservable to a lender in the absence of some other action on the lender's part. A costly state verification (CSV) problem [Townsend (1979), Diamond (1984), Gale and Hellwig (1985), Williamson $(1986,1987)]$ arises because for either type of project, the random return $z$ can be freely observed only by the project owner. For certain other agents the project return can be observed, ex post, if a fixed amount of effort, denoted by $\gamma$, is expended in period 2. Also, we will allow for the possibility that only some agents can engage in state verification, as we describe below.

The moral hazard problem in the model works as follows. Since a lender does not observe a borrower's choice of investment project ex ante, a borrower who receives $\mathrm{q}_{1}$ units of external funding in period 1 could operate project 2 , and divert $\mathrm{q}_{1}-\mathrm{q}_{2}$ units to other uses. To fix ideas, we assume that diverted funds yield "perks" to firm owners. A firm owner (borrower) who has a second period income of $\mathrm{y}$ and who has expended $\mathrm{q}_{1}-\mathrm{q}_{2}$ units of funds on "perks" has the utility level $\mathrm{y}+\delta\left(\mathrm{q}_{1}-\mathrm{q}_{2}\right)$. The parameter $\delta$ describes how close a substitute "perks" are for other income. We assume that $\delta \in(0,1]$, and that $\hat{z}_{2}>\delta .8$

While only a borrower knows his own project choice ex ante, this choice can be ascertained ex post by a lender by engaging in what we term interim monitoring. In particular, after an investment has occurred (it is then no longer reversible), but before the project return is realized, a lender can learn the true choice of project by expending $\lambda$ units of effort. At this point, if the borrower has diverted funds, the lender can call the loan and liquidate the project. Projects of type $\mathrm{j}$ have the liquidation value $\mathrm{L}_{\mathrm{j}}$. We 
assume that interim monitoring can be done stochastically. ${ }^{9}$ However, any "perks" consumption generated by the diversion of funds occurs before a project can be liquidated. ${ }^{10}$

Interim monitoring is one device by which a lender can attempt to control the moral hazard problem. A second device is also available. In particular, we assume that each borrower can deal with only a single lender, so that that lender can control the quantity of funds the borrower receives. ${ }^{11}$ Thus, by restricting the quantity of funds loaned to $\mathrm{q}_{2}$, a lender can always prevent a diversion of funds. If $\mathrm{q}_{1}$ is lent, a moral hazard problem is always potentially present.

\section{Discussion}

The purpose of introducing a CSV problem is that it creates some presumption that the debt contracts entered into by commercial banks are not an inferior contractual form, so long as we abstract from stochastic monitoring. Thus we focus here on deterministic state verification. ${ }^{12}$ The purpose of introducing moral hazard is to permit an investigation of how FDIC behavior affects the incentives of banks to address problems of moral hazard.

\section{B. Bankers}

Agents with the ability to form banks constitute a fraction $\beta \in(0,1)$ of the population. Each potential banker is endowed with one unit of first period funds, along with some effort that can be expended on interim and ex post monitoring. In order to actuate the ability to engage in monitoring (perhaps by making an investment), a potential banker must invest one unit of funds in the first period. Since a bank requires monitoring capacity, this assumption implies that each active bank must obtain external deposits to lend.

Our assumptions on investment returns imply that there is no aggregate uncertainty in this economy. Of course, to create a role for deposit insurance, it is necessary to allow for the possibility that any bank might fail. To accomplish this we assume that any given bank has a limited ability to service 
and monitor loans and - in particular-can make only a finite number of loans. Under this assumption, complete diversification is impossible for any bank. To simplify matters we assume that each bank deals with only a single borrower. ${ }^{13}$

Bankers are assumed to be risk neutral, and to care only about second period income (consumption) and effort expended on monitoring. If $\mathrm{y}$ denotes second period income and $\mathrm{e}_{\mathrm{I}}\left(\mathrm{e}_{\mathrm{F}}\right)$ denotes effort expenditure on interim (final) monitoring, then a banker's utility is $\mathrm{y}-\lambda \mathrm{e}_{\mathrm{I}}-\gamma \mathrm{e}_{\mathrm{F}} \cdot \mathrm{e}_{\mathrm{I}}\left(\mathrm{e}_{\mathrm{F}}\right) \in\{0,1\}$, and $\mathrm{e}_{\mathrm{I}}\left(\mathrm{e}_{\mathrm{F}}\right)=0(1)$ implies that interim (ex post) monitoring did not (did) occur.

Finally, as the phrase "potential banker" indicates, each potential banker need not run a bank. A potential banker who is not active in banking simply saves his single unit of funds, in effect becoming a depositor. We impose the assumption $\beta \geq \alpha$, so that it is at least possible that every potential borrower can gain access to a bank.

\section{Depositors}

The remainder of the population, having mass $1-\alpha-\beta$, is depositors. All depositors are endowed with one unit of funds when young, and depositors care only about second period consumption. Thus, depositors inelastically supply one unit of funds, per capita, in the initial period.

Depositors are risk averse, so they desire deposit insurance. Given our assumptions on the inability of banks to diversify, this insurance is provided by the FDIC. Parenthetically, note that our assumption that $\mathrm{q}_{2}>1$ means that any firm requires more funds than a single saver could provide even absent any investment in monitoring capacity. Familiar arguments [Diamond (1984), Williamson (1986)] then imply the desirability of having savings be intermediated, in order to reduce the duplication of monitoring effort. 


\section{Deposits}

Prior to describing deposit insurance we need to describe the operation of deposit markets. In the first period all depositors - as well as potential bankers not operating banks - make a deposit with active banks. Banks promise to pay the gross market rate of return $r$, per unit deposited, if it is feasible for them to do so. Banks lending to sufficiently successful borrowers will be able to honor their commitments. However, for banks who lend to borrowers experiencing low returns, it will be infeasible to pay off depositors. In this case the bank fails and the FDIC pays off depositors. We now describe FDIC behavior.

\section{E. Deposit Insurance}

The risk aversion of depositors renders deposit insurance valuable. The fact that there is no aggregate uncertainty implies that it is feasible for the FDIC to fully insure depositors. The FDIC behaves as follows. In period one the FDIC imposes a flat rate deposit insurance premium of $\mathrm{t}$ per unit lent on each active bank. ${ }^{14}$ It also collects some other revenue, which we describe below.

In period two, some banks pay $\mathrm{r}$ per unit deposited, and some do not. The FDIC takes no action with respect to the former. However, for the latter, "failed banks", the FDIC takes over the bank, liquidates its assets, and uses the proceeds to pay depositors. Like other agents, the FDIC cannot freely observe the assets of a failed bank. Thus the action of taking over a bank requires that the FDIC engage in costly ex post state verification to ascertain the value of bank assets. To conduct this state verification the FDIC hires private agents, which it can do at a cost of $\gamma$.

The FDIC's revenue from deposit insurance premiums, plus the assets of failed banks, may or may not be sufficient to cover its insurance losses plus its operating expenses (verification costs). Moreover, given the absence of any aggregate uncertainty, any FDIC shortfalls or surpluses are perfectly predictable in period one. We therefore assume that the FDIC can levy lump-sum taxes in the initial period (these taxes may be negative if the FDIC has a surplus) in order to balance its budget. We denote 
this lump-sum tax by $\tau$. In general it will matter who must pay this tax. To illustrate the range of possibilities we consider two scenarios: (a) only depositors (including potential bankers not operating banks) pay this tax, and (b) depositors and funded borrowers pay this tax. Note that, in either case, $\tau$ represents a discounted present value of the FDIC's future shortfalls.

Of course, like other agents the FDIC must transfer the funds it collects in period one into period two. How it does so will potentially matter, as FDIC actions can affect the supply of private credit. Since as a practical matter no one seems concerned that FDIC revenue collection impacts on credit availability, we make the following assumption. The FDIC deposits the proceeds of any lump-sum tax collections, and the payment of deposit insurance premiums, with private banks. This prevents FDIC revenue collection from affecting the supply of credit. In addition, the assumption implies that the FDIC is subject to the same risks as other bank depositors.

\section{Discussion}

Clearly our intention is roughly to model government deposit insurance as it prevails in the U. S. While the FDIC has never needed to obtain funding from general tax revenue it clearly could - and most likely would (possibly in part from seigniorage revenue) — if necessary. Indeed such access to general tax revenue was authorized in the FDICIA Act of 1991.

The same act also provided for deposit insurance premia based on risk, rather than a simple flatrate premium. However, the assumption of a flat-rate premium does little violence to current reality, as an overwhelming majority of banks are in the same (lowest) risk class. And, of course, until relatively recently, a flat-rate insurance premium was in effect in the U. S.

\section{Bank Behavior}

In this section we analyze the optimal behavior of banks. To do so, it is helpful to review the timing of events in the model. First, each potential banker, knowing deposit rates, taxes, and insurance 
premia, decides whether or not to open a bank. Those who act as bankers invest in monitoring capacity, take deposits, and pay their deposit insurance premium. They then enter into a contractual arrangement with (make a loan to) one borrower. After the loan has been made, the borrower decides which project to operate among those that can be operated given his funding. Once the project choice has been made the bank can engage in interim monitoring with a probability of its own choosing. A bank which has monitored can, if funds have been diverted, call the loan. If the investment project is not liquidated at this point, it yields a gross return z, per unit invested, drawn from the appropriate distribution. Subsequent to this realization, payments are made from the borrower to the bank, and verification of the project return is undertaken as called for by the contract. Finally, if it is feasible to do so, the bank pays $\mathrm{r}$ per unit deposited, and retains any residual. Otherwise the bank fails, and is taken over by the FDIC. Of course potential bankers who choose not to operate banks simply become the depositors of other banks.

In keeping with the structure of commercial banking in the U. S., we assume that banks are restricted to engaging in debt contracts. Our notion of a debt contract is drawn from the CSV literature [Diamond (1984), Gale and Hellwig (1985), Williamson (1986)], so that a debt contract consists of the following. (a) A specification of the quantity lent, q. Given our assumptions, it suffices to let $q \in\left\{q_{1}\right.$, $\mathrm{q}_{2}$ \}. (b) A probability, denoted $\mathrm{p}$, that interim monitoring will be undertaken. Clearly if $\mathrm{q}=\mathrm{q}_{2}, \mathrm{p}=0$. (c) A set of states, denoted by A, in which ex post verification will occur. No state verification will occur if $z \in \mathrm{B} \equiv[0, \bar{z}]-\mathrm{A}$. (d) A repayment schedule (per unit borrowed) $\mathrm{R}(z)$, for all $z \in \mathrm{A}$. (e) An uncontingent repayment - which is equivalent to a gross real rate of interest-if $z \in \mathrm{B}$. We denote this payment (per unit borrowed) by x. As in the conventional CSV literature it will be the case that $\mathrm{A}=[0$, $\mathrm{x})$, and that $\mathrm{R}(z)=z$ for all $z \in \mathrm{A}$.

It is apparent that there are only three strategies a bank can follow. (1) Lend $\mathrm{q}_{1}$ to a borrower, and engage in interim monitoring to deter the diversion of funds. (2) Lend $\mathrm{q}_{2}$ to a borrower, so that the borrower is constrained to invest in project 2. (3) Lend $q_{1}$ to a borrower, engage in no interim monitoring, and allow a diversion of funds to occur. Boyd, Chang, and Smith (1998) show that it is never 
optimal for a bank to follow the third strategy. We now consider the other two strategies, which we term strategies 1 and 2 respectively.

\section{A. Strategy 1}

Under strategy 1 a bank extends credit to a borrower in the amount $\mathrm{q}_{1}$, and engages in interim monitoring as necessary to deter moral hazard. Let $\mathrm{x}_{1}$ denote the rate of interest charged by a representative bank following strategy 1 . Then the expected gross return to the bank, exclusive of interim monitoring costs and the cost of funds, is given by

$$
\mathrm{x}_{1}\left[1-\mathrm{G}\left(\mathrm{x}_{1}\right)\right]+\int_{0}^{\mathrm{x}_{1}} z \mathrm{~g}(z) \mathrm{d} z-\left(\gamma / \mathrm{q}_{1}\right) \mathrm{G}\left(\mathrm{x}_{1}\right)=\mathrm{x}_{1}-\int_{0}^{\mathrm{x}_{1}} \mathrm{G}(z) \mathrm{d} z-\left(\gamma / \mathrm{q}_{1}\right) \mathrm{G}\left(\mathrm{x}_{1}\right) \equiv \pi\left(\mathrm{x}_{1}, \mathrm{q}_{1} ; \gamma\right)
$$

per unit lent. The expected payoff to the borrower, if he invests in project 1 , is

$$
\mathrm{q}_{1}\left\{\hat{z}_{1}-\mathrm{x}_{1}\left[1-\mathrm{G}\left(\mathrm{x}_{1}\right)\right]-\int_{0}^{\mathrm{x}_{1}} z \mathrm{~g}(z) \mathrm{d} z\right\}=\mathrm{q}_{1}\left\{\hat{z}_{1}-\mathrm{x}_{1}+\int_{0}^{\mathrm{x}_{1}} \mathrm{G}(z) \mathrm{d} z\right\}
$$

In order to determine the severity of the moral hazard problem, we also need to know the borrower's expected payoff from the diversion of funds. A borrower who receives a loan of $\mathrm{q}_{1}$, invests in project 2, and expends $\mathrm{q}_{1}-\mathrm{q}_{2}$ units of funds on "perks", defaults on his loan if $z<\mathrm{q}_{1} \mathrm{x}_{1} / \mathrm{q}_{2}$. As a result, in the absence of any interim monitoring, the expected payoff to funds diversion would be

$$
\begin{aligned}
& \mathrm{q}_{2} \hat{z}_{2}+\delta\left(\mathrm{q}_{1}-\mathrm{q}_{2}\right)-\mathrm{q}_{1} \mathrm{x}_{1}\left\{1-\mathrm{F}\left[\left(\mathrm{q}_{1} / \mathrm{q}_{2}\right) \mathrm{x}_{1}\right]\right\}-\mathrm{q}_{2} \int_{0}^{\left(\mathrm{q}_{1} / \mathrm{q}_{2}\right) \mathrm{x}_{1}} z \mathrm{f}(z) \mathrm{d} z=\mathrm{q}_{2} \hat{z}_{2}+\delta\left(\mathrm{q}_{1}-\mathrm{q}_{2}\right)- \\
& \mathrm{q}_{1} \mathrm{x}_{1}+\mathrm{q}_{2} \int_{0}^{\left(\mathrm{q}_{1} / \mathrm{q}_{2}\right) \mathrm{x}_{1}} \mathrm{~F}(z) \mathrm{d} z .
\end{aligned}
$$


If the borrower's payoff from borrowing $\mathrm{q}_{1}$, investing in project 2 , and expending $\mathrm{q}_{1}-\mathrm{q}_{2}$ on perks exceeds the payoff from investing in project 1 , there is a nontrivial moral hazard problem. Thus interim monitoring is required to deter moral hazard if

$$
\mathrm{q}_{2} \hat{z}_{2}+\delta\left(\mathrm{q}_{1}-\mathrm{q}_{2}\right)>\mathrm{q}_{1} \hat{z}_{1}+\mathrm{q}_{1} \int_{0}^{\mathrm{X}_{1}} \mathrm{G}(z) \mathrm{d} z-\mathrm{q}_{2} \int_{0}^{\left(\mathrm{q}_{1} / \mathrm{q}_{2}\right) \mathrm{X}_{1}} \mathrm{~F}(z) \mathrm{d} z
$$

holds, as we henceforth assume. Note that (a.2) will necessarily hold if $\mathrm{x}_{1}$ is sufficiently large. In other words, sufficiently high loan rates lead to a problem of moral hazard. We also assume that

$$
\text { (a.3) } \bar{z}>\left(\mathrm{q}_{1} / \mathrm{q}_{2}\right) \mathrm{x}_{1}
$$

Assumption (a.3) implies that a borrower who did engage in funds diversion would not default on his loan with probability one.

Since (a.2) obtains, a bank following strategy 1 must engage in interim monitoring with a probability sufficiently great to deter funds diversion. If this interim monitoring occurs, and if the borrower has diverted funds, recall that the lender liquidates the project. However, the borrower consumes "perks", under our timing conventions, prior to this liquidation. If the borrower diverts funds and interim monitoring fails to occur, the borrower gets the payoff described above. Hence, to deter misallocation of funds, a lender must choose an interim monitoring probability $\mathrm{p}$ to satisfy the following incentive constraint:

$$
\mathrm{q}_{1}\left\{\hat{z}_{1}-\mathrm{x}_{1}+\int_{0}^{\mathrm{X}_{1}} \mathrm{G}(z) \mathrm{d} z\right\} \geq(1-\mathrm{p})\left\{\mathrm{q}_{2} \hat{z}_{2}-\mathrm{q}_{1} \mathrm{x}_{1}+\mathrm{q}_{2} \int_{0}^{\left(\mathrm{q}_{1} / \mathrm{q}_{2}\right) \mathrm{X}_{1}} \mathrm{~F}(z) \mathrm{d} z\right\}+\delta\left(\mathrm{q}_{1}-\mathrm{q}_{2}\right) .
$$


Given the costs of interim monitoring this should occur as infrequently as possible. Thus the interim monitoring probability is

$$
\begin{aligned}
& \mathrm{p}=\left\{\mathrm{q}_{2} \hat{z}_{2}+\delta\left(\mathrm{q}_{1}-\mathrm{q}_{2}\right)-\mathrm{q}_{1} \hat{z}_{1}+\mathrm{q}_{2} \int_{0}^{\left(\mathrm{q}_{1} / \mathrm{q}_{2}\right) \mathrm{x}_{1}} \mathrm{~F}(z) \mathrm{d} z-\mathrm{q}_{1} \int_{0}^{\mathrm{x}_{1}} \mathrm{G}(z) \mathrm{d} z\right\} /\left\{\mathrm{q}_{2} \hat{z}_{2}-\mathrm{q}_{1} \mathrm{x}_{1}+\right. \\
& \left.\mathrm{q}_{2} \int_{0}^{\left(\mathrm{q}_{1} / \mathrm{q}_{2}\right) \mathrm{x}_{1}} \mathrm{~F}(z) \mathrm{d} z\right\} \equiv \mathrm{p}\left(\mathrm{x}_{1}\right) .
\end{aligned}
$$

Clearly $\mathrm{p}^{\prime}\left(\mathrm{x}_{1}\right)>0$ holds. As the loan rate rises under strategy 1 the moral hazard problem becomes more severe; hence monitoring must occur, on average, more frequently. In addition, since $\mathrm{p}\left(\mathrm{x}_{1}\right) \leq 1$ must hold, (3) imposes a constraint on $\mathrm{x}_{1}$ :

$$
\mathrm{q}_{1} \hat{z}_{1}-\delta\left(\mathrm{q}_{1}-\mathrm{q}_{2}\right) \geq \mathrm{q}_{1} \mathrm{x}_{1}-\mathrm{q}_{1} \int_{0}^{\mathrm{x}_{1}} \mathrm{G}(z) \mathrm{d} z
$$

must be satisfied; otherwise it is impossible to deter moral hazard. Let $\tilde{x}$ denote the value of $\mathrm{x}_{1}$ satisfying (4) at equality. Then (4) is equivalent to $x_{1} \leq \tilde{x}$.

It follows from this discussion that the expected return to a bank from following strategy 1 and charging the interest rate $x_{1}$ is (not inclusive of the cost of funds) $q_{1} \pi\left(x_{1}, q_{1} ; \gamma\right)-\lambda p\left(x_{1}\right)$. We now describe the determination of $\mathrm{x}_{1}$.

\section{Interest Rates under Credit Rationing}

As is well-known [Williamson (1986), (1987)], the function $\pi$ is typically not monotone in $\mathrm{x}_{1}$. In particular, even absent the moral hazard problem, excessively high rates of interest lead to high probabilities of default, high expected monitoring costs, and low returns to lenders. The presence of a moral hazard problem reinforces the negative consequences of high loan rates. 
When $\mathrm{q}_{1} \pi\left(\mathrm{x}_{1}, \mathrm{q}_{1} ; \gamma\right)-\lambda \mathrm{p}\left(\mathrm{x}_{1}\right)$ is not monotone in $\mathrm{x}_{1}$, this introduces the possibility that credit may be rationed. In particular, borrowers who fail to obtain funding may not be able to compete with funded borrowers who receive credit since, beyond some point, bidding up the loan rate simply reduces the expected return to a lender. Thus if funds supply is low relative to potential loan demand, credit rationing can occur.

It simplifies our discussion to focus on equilibria where credit is rationed. ${ }^{15}$ When credit rationing obtains, loan rates are bid up to the level that maximizes a lender's expected payoff, not inclusive of the cost of funds. Hence the equilibrium loan rate under strategy $1, \hat{x}_{1}$, is the solution to the following problem:

(P. 1) maximize $\mathrm{q}_{1} \pi\left(\mathrm{x}_{1}, \mathrm{q}_{1} ; \gamma\right)-\lambda \mathrm{p}\left(\mathrm{x}_{1}\right)$

subject to $\mathrm{x}_{1} \leq \widetilde{\mathrm{x}}$ and

$$
\mathrm{q}_{1}\left\{\hat{z}_{1}-\mathrm{x}_{1}-\int_{0}^{\mathrm{X}_{1}} \mathrm{G}(z) \mathrm{d} z\right\} \geq \bar{u}
$$

\section{The Cost of Funds}

A bank following strategy 1 requires $\mathrm{q}_{1}$ units of funds to lend, and $\mathrm{tq}_{1}$ units of funds to pay its deposit insurance premiums. Thus the bank will have deposits of $(1+t) \mathrm{q}_{1}$, and it will owe its depositors $\mathrm{r}(1+\mathrm{t}) \mathrm{q}_{1}$ in the second period. The bank will be able to honor its obligations to depositors if its borrower has a return $z \geq \mathrm{r}(1+\mathrm{t})$. Otherwise the bank will fail. Clearly failure occurs with probability $\mathrm{G}[\mathrm{r}(1+$ t)].

In the event of a failure, the FDIC will take over the bank and liquidate all assets to pay off depositors. Let $\Phi_{1}[\mathrm{r}(1+\mathrm{t})]$ denote the bank's expected payments to depositors and the FDIC under strategy 1 (per unit lent). Then $\Phi_{1}$ is given by 


$$
\Phi_{1}[\mathrm{r}(1+\mathrm{t})]=\mathrm{r}(1+\mathrm{t})\{1-\mathrm{G}[\mathrm{r}(1+\mathrm{t})]\}+\int_{0}^{r(1+t)} z \mathrm{~g}(z) \mathrm{d} z=\mathrm{r}(1+\mathrm{t})-\int_{0}^{r(1+t)} \mathrm{G}(z) \mathrm{d} z
$$

Clearly $\Phi_{1}^{\prime}>0$, so that higher interest rates or higher deposit insurance premia increase the bank's cost of funds.

\section{Net Payoff}

The bank's net payoff from following strategy 1 is $\mathrm{q}_{1}\left\{\pi\left(\hat{x}_{1}, \mathrm{q}_{1} ; \gamma\right)-\Phi_{1}[\mathrm{r}(1+\mathrm{t})]\right\}-\lambda \mathrm{p}\left(\hat{x}_{1}\right)$, if credit is rationed.

\section{B. Strategy 2}

A bank following strategy 2 lends a borrower $\mathrm{q}_{2}$. Funds diversion is then infeasible. ${ }^{16}$ Therefore, under strategy 2, the borrower simply invests in a type 2 project. Of course, the pursuit of strategy 2 implies that interim monitoring is unnecessary.

Let $\mathrm{x}_{2}$ denote the interest rate charged on loans by a representative bank following strategy 2 (per unit lent). The borrower repays $\mathrm{x}_{2}$ if $z \geq \mathrm{x}_{2}$; otherwise, he defaults. The expected payment from the borrower to the bank is then

$$
\mathrm{q}_{2}\left\{\mathrm{x}_{2}\left[1-\mathrm{F}\left(\mathrm{x}_{2}\right)\right]+\int_{0}^{\mathrm{x}_{2}} z \mathrm{f}(z) \mathrm{d} z\right\}=\mathrm{q}_{2}\left[\mathrm{x}_{2}-\int_{0}^{\mathrm{x}_{2}} \mathrm{~F}(z) \mathrm{d} z\right]
$$

The borrower's expected payoff, if funded, is

$$
\mathrm{q}_{2}\left[\hat{z}_{2}-\mathrm{x}_{2}+\int_{0}^{\mathrm{X}_{2}} \mathrm{~F}(z) \mathrm{d} z\right]
$$


Since a borrower defaults with probability $\mathrm{F}\left(\mathrm{x}_{2}\right)$ under strategy 2, the bank's expected return (per unit lent), not inclusive of its cost of funds, is given by

$$
\mathrm{x}_{2}-\int_{0}^{\mathrm{x}_{2}} \mathrm{~F}(z) \mathrm{d} z-\left(\gamma / \mathrm{q}_{2}\right) \mathrm{F}\left(\mathrm{x}_{2}\right) \equiv \zeta\left(\mathrm{x}_{2}, \mathrm{q}_{2} ; \gamma\right)
$$

The function $\zeta$ has properties similar to those of $\pi$, and hence need not increase monotonically with $\mathrm{x}_{2}$. It follows that credit rationing can once again occur and, as before, we focus on economies where credit is rationed in equilibrium. Therefore, $\mathrm{x}_{2}$ is bid up to the level that maximizes the expected return of a bank pursuing strategy 2 ; that is, $\mathrm{x}_{2}=\hat{x}_{2}$, where $\hat{x}_{2}$ is the solution to the following problem.

(P.2) Maximize $\zeta\left(\mathrm{x}_{2}, \mathrm{q}_{2} ; \gamma\right)$ subject to

$$
\mathrm{q}_{2}\left\{\hat{z}_{2}-\mathrm{x}_{2}+\int_{0}^{\mathrm{X}_{2}} \mathrm{~F}(z) \mathrm{d} z\right\} \geq \bar{u}
$$

Thus the lender's expected return, not inclusive of the cost of funds, is $\mathrm{q}_{2} \zeta\left(\hat{\mathrm{x}}_{2}, \mathrm{q}_{2} ; \gamma\right)$.

\section{The Cost of Funds}

In order to follow strategy 2 , a bank requires $\mathrm{q}_{2}(1+\mathrm{t})$ units of funds to make loans of $\mathrm{q}_{2}$ and to pay its deposit insurance premium. In the second period the bank therefore has interest obligations of $\mathrm{r}(1$ $+\mathrm{t}) \mathrm{q}_{2}$, and it will be able to meet these iff $z \geq \mathrm{r}(1+\mathrm{t}) \mathrm{q}_{2}$. It follows that the bank fails with probability $\mathrm{F}\left[\mathrm{r}(1+\mathrm{t}) \mathrm{q}_{2}\right]$, in which case the FDIC takes control of the bank's assets. Thus, if $\Phi_{2}[\mathrm{r}(1+\mathrm{t})]$ denotes the bank's expected payments to depositors and the FDIC (per unit lent) under strategy 2, we have 


$$
\Phi_{2}[\mathrm{r}(1+\mathrm{t})]=\mathrm{r}(1+\mathrm{t})\{1-\mathrm{F}[\mathrm{r}(1+\mathrm{t})]\}-\int_{0}^{\mathrm{r}(1+\mathrm{t})} z \mathrm{f}(z) \mathrm{d} z=\mathrm{r}(1+\mathrm{t})-\int_{0}^{\mathrm{r}(1+\mathrm{t})} \mathrm{F}(z) \mathrm{d} z
$$

Observe that assumption (a.1) implies that $\Phi_{2}[\mathrm{r}(1+\mathrm{t})] \leq \Phi_{1}[\mathrm{r}(1+\mathrm{t})]$, so that the expected cost of funds (per unit) is lower under strategy 2 then under strategy 1, ceteris paribus. This reflects the higher default probability under strategy 2 . Finally, of course, $\Phi_{2}^{\prime}>0$ holds.

\section{Net Payoffs}

Clearly the net expected payoff to a bank under strategy 2 is $\mathrm{q}_{2}\left\{\zeta\left(\hat{x}_{2}, \mathrm{q}_{2} ; \gamma\right)-\Phi_{2}[\mathrm{r}(1+\mathrm{t})]\right\}$, if credit is rationed.

\section{Optimal Bank Behavior}

It remains to describe when it is optimal for banks to follow strategy 1 or strategy 2. To do so, the following notation will be helpful. Let

$$
\bar{\pi}_{1} \equiv \mathrm{q}_{1} \pi\left(\hat{x}_{1}, \mathrm{q}_{1} ; \gamma\right)-\lambda \mathrm{p}\left(\hat{x}_{1}\right)
$$

$$
\bar{\pi}_{2} \equiv \mathrm{q}_{2} \zeta\left(\hat{x}_{2}, \mathrm{q}_{2} ; \gamma\right)
$$

Then $\bar{\pi}_{1}\left(\bar{\pi}_{2}\right)$ is the expected net payoff to the bank, inclusive of monitoring costs, but not inclusive of the cost of funds, from following strategy $1(2) .{ }^{17}$ Note that under credit rationing, the values $\bar{\pi}_{1}$ and $\bar{\pi}_{2}$ are independent of any other endogenous variables. Finally, define $\eta$ by $\eta \equiv r(1+t)$. A bank fails under either strategy if its borrower's investment return satisfies $z<\eta$.

It follows from our previous discussion that banks strictly prefer strategy 1 to strategy 2 iff 


$$
\left(\mathrm{q}_{1}-\mathrm{q}_{2}\right) \eta-\mathrm{q}_{1} \int_{0}^{\eta}\left[\mathrm{G}(z)-\left(\mathrm{q}_{2} / \mathrm{q}_{1}\right) \mathrm{F}(z)\right] \mathrm{d} z<\bar{\pi}_{1}-\bar{\pi}_{2}
$$

Observe that if $\bar{\pi}_{1} \leq \bar{\pi}_{2}$, then strategy 1 is never preferred to strategy 2 . However, if $\bar{\pi}_{1}>\bar{\pi}_{2}$, define the value $\eta^{*}$ by

$$
\left(\mathrm{q}_{1}-\mathrm{q}_{2}\right) \eta^{*}-\mathrm{q}_{1} \int_{0}^{\eta^{*}}\left[\mathrm{G}(\mathrm{z})-\left(\mathrm{q}_{2} / \mathrm{q}_{1}\right) \mathrm{F}(z)\right] \mathrm{d} z \equiv \bar{\pi}_{1}-\bar{\pi}_{2} .
$$

It is easy to verify that (13) uniquely defines a value $\eta^{*}>0$.

We can now summarize optimal bank behavior as follows. (a) If $\bar{\pi}_{1} \leq \bar{\pi}_{2}$, holds, stategy 2 is optimal for all values of $\eta$. (b) If $\bar{\pi}_{1}>\bar{\pi}_{2}$, and if $\eta<(>) \eta^{*}$, strategy 1 (2) is optimal for banks. (c) If $\eta=\eta^{*}$, strategy 1 and strategy 2 yield identical expected payoffs, and banks are indifferent between them.

Intuitively, a bank's cost of funds (per unit and total) is higher under strategy 1 than under strategy 2. If $\mathrm{r}(1+\mathrm{t})$ is small, this effect is not large, and if $\bar{\pi}_{1}>\bar{\pi}_{2}$ holds, banks will prefer strategy 1 . However, as $r(1+t)$ increases, a bank's cost of funds under strategy 1 rises relative to strategy 2 . Thus large values of $r(1+t)$ will imply that strategy 2 is optimal.

\section{Optimal Bank Behavior under Alternative FDIC Funding Schemes}

The previous discussion is predicated on the FDIC making up any revenue shortfalls by imposing a lump-sum tax on depositors alone. We now describe how the analysis must be modified when the FDIC collects lump-sum taxes both from depositors and funded borrowers.

When lump-sum taxes are paid by funded borrowers as well as depositors, matters differ as follows. In addition to the funds required to operate their projects, funded borrowers must obtain an 
additional $\tau$ units of credit from banks in the first period to pay their taxes. Thus under strategy 1 (2) a funded borrower obtains a loan of $\mathrm{q}_{1}+\tau\left(\mathrm{q}_{2}+\tau\right)$. The borrower defaults on the loan if the project return satisfies $z<\mathrm{x}_{1}\left(\mathrm{q}_{1}+\tau\right) / \mathrm{q}_{1}\left[z<\mathrm{x}_{2}\left(\mathrm{q}_{2}+\tau\right) / \mathrm{q}_{2}\right]$, where $\mathrm{x}_{1}\left(\mathrm{x}_{2}\right)$ is the rate of interest charged by banks under strategy 1 (2). In addition, a bank following strategy 1 (2) must obtain deposits in the amount $\left(\mathrm{q}_{1}+\tau\right)(1+\mathrm{t})\left[\left(\mathrm{q}_{2}+\tau\right)(1+\mathrm{t})\right]$. The bank fails under strategy $1(2)$ if the return on the borrower's project satisfies $z<\mathrm{r}(1+\mathrm{t})\left(\mathrm{q}_{1}+\tau\right) / \mathrm{q}_{1} \quad\left[z<\mathrm{r}(1+\mathrm{t})\left(\mathrm{q}_{2}+\tau\right) / \mathrm{q}_{2}\right]$. From these observations it follows that a bank's expected payoff under strategy 1 is given by

$$
\mathrm{q}_{1}\left\{\pi\left[\mathrm{x}_{1}\left(\mathrm{q}_{1}+\tau\right) / \mathrm{q}_{1}, \mathrm{q}_{1} ; \gamma\right]-\Phi_{1}\left[\mathrm{r}(1+\mathrm{t})\left(\mathrm{q}_{1}+\tau\right) / \mathrm{q}_{1}\right]\right\}-\lambda \mathrm{p}\left[\mathrm{x}_{1}\left(\mathrm{q}_{1}+\tau\right) / \mathrm{q}_{1}\right]
$$

Therefore, if credit is rationed, a bank pursuing strategy 1 will set its interest rate so that $\mathrm{x}_{1}=\mathrm{q}_{1} \hat{x}_{1} /\left(\mathrm{q}_{1}+\right.$ $\tau)$. Similarly, the expected payoff of a bank following strategy 2 is

$$
\mathrm{q}_{2}\left\{\zeta\left[\mathrm{x}_{2}\left(\mathrm{q}_{2}+\tau\right) / \mathrm{q}_{2}, \mathrm{q}_{2} ; \gamma\right]-\Phi_{2}\left[\mathrm{r}(1+\mathrm{t})\left(\mathrm{q}_{2}+\tau\right) / \mathrm{q}_{2}\right]\right\}
$$

Therefore, if credit is rationed, $x_{2}=\mathrm{q}_{2} \hat{x}_{2} /\left(\mathrm{q}_{2}+\tau\right)$ will hold.

It is now apparent that strategy 1 (2) is strictly preferred by banks if

$$
\bar{\pi}_{1}-\bar{\pi}_{2}>(<) \mathrm{q}_{1} \Phi_{1}\left[\eta\left(\mathrm{q}_{1}+\tau\right) / \mathrm{q}_{1}\right]-\mathrm{q}_{2} \Phi_{2}\left[\eta\left(\mathrm{q}_{2}+\tau\right) / \mathrm{q}_{2}\right]
$$

As before, it is immediate that if $\bar{\pi}_{1} \leq \bar{\pi}_{2}$, strategy 2 is always optimal for banks. However, if $\bar{\pi}_{1}>\bar{\pi}_{2}$, the optimal bank strategy depends on the prevailing value of $\eta$.

Define $\bar{\eta}(\tau)$ by 


$$
\bar{\pi}_{1}-\bar{\pi}_{2} \equiv \mathrm{q}_{1} \Phi_{1}\left[\bar{\eta}(\tau)\left(\mathrm{q}_{1}+\tau\right) / \mathrm{q}_{1}\right]-\mathrm{q}_{2} \Phi_{2}\left[\bar{\eta}(\tau)\left(\mathrm{q}_{2}+\tau\right) / \mathrm{q}_{2}\right]
$$

if $\bar{\pi}_{1}>\bar{\pi}_{2}$. Then it is easy to check that $\bar{\eta}(\tau)$ is uniquely defined for all $\tau>-\mathrm{q}_{2}$, and that $\bar{\eta}(\tau)>0$. It is also easy to show that strategy 1 (2) is optimal for banks if $\eta<(>) \bar{\eta}(\tau)$. Finally, if $\eta=\bar{\eta}(\tau)$, then banks are indifferent between following strategies 1 and 2 .

It follows by differentiating (15) that $\bar{\eta}^{\prime}(\tau)>0$ holds. Thus the higher the lump-sum tax (in effect, the larger are FDIC expected losses), the higher is the "boundary" between values of $r(1+t)$ where strategy 1 is optimal, and values of $\mathrm{r}(1+\mathrm{t})$ where strategy 2 is optimal. Intuitively, when funded borrowers must pay the lump-sum tax, banks must lend more and raise more funds. This has an effect on a bank's cost of funds, and the effect is different under the two strategies. Clearly the proportional effect of a change in $\tau$ is larger under strategy 2 than strategy 1; thus the magnitude of $\tau$ affects a bank's relative ranking of the two strategies for any value of $\eta$. This effect is summarized in the function $\bar{\eta}(\tau)$.

\section{General Equilibrium}

There are three conditions that must be satisfied by a full general equilibrium. First, sources and uses of funds must be equal. Second, the FDIC budget must balance. And third, the assumption that $\beta \geq$ $\alpha$, coupled with our focus on credit rationing (not all potential borrowers can be funded, in equilibrium), implies that not all potential bankers can operate banks. Therefore, potential bankers must be indifferent between operating banks, and acting as depositors. In effect, banks must earn "normal profits."

We now describe the determination of equilibrium in this economy. As before, we begin with the assumption that lump-sum taxes are levied only on depositors. We then describe how the analysis is modified when lump-sum taxes are also paid by funded borrowers. 


\section{A. "Normal" Profits for Banks}

As we know from the previous section, strategy 1 (2) is optimal for banks if $\eta \leq(\geq) \eta^{*}$. Then define the function $Q$ by

$$
\mathrm{Q}(\eta ; \gamma, \lambda) \equiv \quad \begin{aligned}
& \bar{\pi}_{1}-\mathrm{q}_{1} \Phi_{1}(\eta) ; \eta \leq \eta^{*} \\
& \bar{\pi}_{2}-\mathrm{q}_{2} \Phi_{2}(\eta) ; \eta \geq \eta^{*}
\end{aligned}
$$

The function Q gives the maximum expected payoff obtainable by a bank given $\eta \equiv \mathrm{r}(1+\mathrm{t})$.

A potential banker who does not operate a bank will pay the lump-sum tax $\tau$ to the FDIC, and will then deposit his after-tax endowment, $1-\tau$, with a bank. His second period gross income (and utility) will therefore be $r(1-\tau)=\eta(1-\tau) /(1+t)$. It follows that potential bankers are indifferent between being bankers and depositors if

$$
\mathrm{Q}(\eta ; \gamma, \lambda)=\eta(1-\tau) /(1+\mathrm{t})
$$

Equation (17) describes a relationship between $\eta$ and the policy variables $t$ and $\tau$ that must hold in order for banks to earn normal profits.

\section{B. Sources Equal Uses of Funds}

Let $\theta$ denote the fraction of potential borrowers who receive funding, and let $q(\eta)$ denote the loan quantity received by a funded borrower as a function of $\eta$. Our previous observations imply that

$$
q(\eta)=\begin{aligned}
& q_{1} ; \eta<\eta^{*} \\
& q_{2} ; \eta>\eta^{*} .
\end{aligned}
$$


Then uses of funds are $\alpha \theta q(\eta)$.

With respect to sources of funds, each agent who is not a borrower or an active bank supplies one unit of funds inelastically. Since the measure of active banks must equal the measure of funded borrowers (due to our "one-bank-one-borrower" assumption), sources of funds are $1-\alpha(1+\theta){ }^{18}$ Then sources of funds and uses of funds are equal if

$$
\theta=(1-\alpha) / \alpha\{1+q[r(1+t)]\}
$$

Note that $\theta<1$ must hold (credit must be rationed) if $(1-\alpha) / \alpha\left(1+\mathrm{q}_{2}\right)<1$ is satisfied, as we henceforth assume.

\section{The FDIC "Break-Even" Condition}

Since $\alpha \theta$ is the measure of active banks, and since each active bank lends $q(\eta)$, the FDIC collects $\alpha \theta \operatorname{tq}(\eta)$ in deposit insurance premiums. In addition, $1-\alpha(1+\theta)$ is the measure of agents who make bank deposits, and each of them pays the lump-sum tax $\tau$ to support the FDIC. By assumption the FDIC redeposits this income with private banks, earning $\mathrm{r}$ per unit deposited in the second period. Thus total second period FDIC income — not inclusive of the assets of failed banks — equals

$$
\begin{aligned}
& \mathrm{r}\{\alpha \theta \operatorname{tq}(\eta)+[1-\alpha(1+\theta)] \tau\}=(1-\alpha) r(t+\tau) \mathrm{q}(\eta) /[1+\mathrm{q}(\eta)]= \\
& (1-\alpha) \eta(\mathrm{t}+\tau) \mathrm{q}(\eta) /(1+\mathrm{t})[1+\mathrm{q}(\eta)] .
\end{aligned}
$$

Total FDIC obligations in period two are computed as follows. Each bank has an expected payment to depositors and (if it fails) the FDIC of $\mathrm{q}_{1} \Phi_{1}(\eta)\left[\mathrm{q}_{2} \Phi_{2}(\eta)\right]$ if strategy 1 (2) is optimal. Thus, since the set of banks is large, FDIC payments to the depositors of failed banks (including itself) equal $\mathrm{q}_{1}\left[\eta-\Phi_{1}(\eta)\right]\left(\mathrm{q}_{2}\left[\eta-\Phi_{2}(\eta)\right)\right.$ per bank if strategy 1 (2) is being followed by banks. With $\alpha \theta$ being the 
measure of active banks, it follows that net FDIC payments to the depositors of failed banks is given by $\alpha \theta \mathrm{q}_{1}\left[\eta-\Phi_{1}(\eta)\right]\left(\alpha \theta \mathrm{q}_{2}\left[\eta-\Phi_{2}(\eta)\right]\right)$ if $\eta<(>) \eta^{*}$

Finally, of course, the FDIC must conduct costly ex post state verification for all failed banks. Since a fraction $G(\eta)[F(\eta)]$ of all banks fail under strategy 1 (2), FDIC monitoring costs equal $\alpha \theta G(\eta)[\alpha \theta F(\eta)]$ if $\eta<(>) \eta^{*}$.

From these observations, it follows that net FDIC costs and net FDIC revenues are equal if

(20.a) $\mathrm{r}\left\{\alpha \theta \operatorname{tq}_{1}+[1-\alpha(1+\theta)] \tau\right\}=\alpha \theta \mathrm{q}_{1}\left[\eta-\Phi_{1}(\eta)\right]+\alpha \theta \mathrm{G}(\eta) ; \eta<\eta *$

(20.b) $\mathrm{r}\left\{\alpha \theta \operatorname{tq}_{2}+[1-\alpha(1+\theta)] \tau\right\}=\alpha \theta \mathrm{q}_{2}\left[\eta-\Phi_{2}(\eta)\right]+\alpha \theta \mathrm{F}(\eta) ; \eta>\eta *$,

where in each case $\theta$ is given by (19). Using (19) in (20), the FDIC breaks even if

(21.a) $\eta(\mathrm{t}+\tau) /(1+\mathrm{t})=\eta-\Phi_{1}(\eta)+\left(\gamma / \mathrm{q}_{1}\right) \mathrm{G}(\eta) ; \eta<\eta^{*}$

(21.b) $\eta(\mathrm{t}+\tau) /(1+\mathrm{t})=\eta-\Phi_{2}(\eta)+\left(\gamma / \mathrm{q}_{2}\right) \mathrm{F}(\eta) ; \eta>\eta^{*}$

\section{General Equilibrium}

Equations (21.a) and (21.b) can be rearranged to yield

(22.a) $\eta(1-\tau) /(1+\mathrm{t})=\Phi_{1}(\eta)-\left(\gamma / \mathrm{q}_{1}\right) \mathrm{G}(\eta) ; \eta<\eta^{*}$

(22.b) $\eta(1-\tau) /(1+\mathrm{t})=\Phi_{2}(\eta)-\left(\gamma / \mathrm{q}_{2}\right) \mathrm{F}(\eta) ; \eta>\eta^{*}$. 
Substituting (22.a) and (22.b) into (17), we obtain the condition that determines the equilibrium value of $\eta \equiv \mathrm{r}(1+\mathrm{t})$

$$
Q(\eta ; \gamma, \lambda)=\begin{aligned}
& \Phi_{1}(\eta)-\left(\gamma / \mathrm{q}_{1}\right) \mathrm{G}(\eta) ; \eta<\eta^{*} \\
& \Phi_{2}(\eta)-\left(\gamma / \mathrm{q}_{2}\right) \mathrm{F}(\eta) ; \eta>\eta^{*} .
\end{aligned}
$$

It is apparent from (13) that the value $\eta *$ depends on parameters alone. Given this observation, it is then equally apparent that (23) determines the equilibrium value(s) $\eta$ totally independently of the policy variables $t$ and $\tau$. In other words, FDIC deposit insurance pricing — and FDIC losses — are totally irrelevant to the determination of $\eta$. And, since the expected payoff to banks is simply $Q(\eta ; \gamma, \lambda)$, the welfare of bankers is also independent of FDIC policy. Finally, the welfare of depositors depends only on $r(1-\tau)=\eta(1-\tau) /(1+t)$. Once $\eta$ is determined this value is given by (22), and hence again is independent of FDIC policy. We therefore have the following result.

PRoposition 1. The equilibrium values of any variables that affect welfare are independent of FDIC policy choices.

In short, it matters absolutely not at all whether or not the FDIC engages in actuarially fair pricing of deposit insurance. Nor does it matter whether there is an implicit subsidy $(\tau>0)$ in the way the FDIC prices deposit insurance. Under the scheme for making up FDIC shortfalls considered here, the conduct of FDIC policy is irrelevant to all agents.

1. More on the Determination of Equilibrium

Define the function $\mathrm{E}(\eta ; \gamma, \lambda)$ by 


$$
\begin{aligned}
& \mathrm{E}(\eta ; \gamma, \lambda) \equiv \bar{\pi}_{1}-\left(\mathrm{q}_{1}+1\right) \Phi_{1}(\eta)+\left(\gamma / \mathrm{q}_{1}\right) \mathrm{G}(\eta) ; \eta<\eta^{*} \\
& \mathrm{E}(\eta ; \gamma, \lambda) \equiv \bar{\pi}_{2}-\left(\mathrm{q}_{2}+1\right) \Phi_{2}(\eta)+\left(\gamma / \mathrm{q}_{2}\right) \mathrm{F}(\eta) ; \eta>\eta^{*} .
\end{aligned}
$$

It is readily verified that the function $E$ is continuous and differentiable for all $\eta \neq \eta^{*}$ and that, where $E_{1}$ is defined, $\mathrm{E}_{1}<0$ for all $\eta<\min \left\{\hat{x}_{2}, \hat{x}_{1}\right\}$. In addition, equilibrium values of $\eta$ satisfy $\mathrm{E}(\eta ; \gamma, \lambda)=0$.

We can now represent the determination of the equilibrium value(s) $\eta$ diagrammatically. Figure 1 depicts three cases. ${ }^{19}$

Case 1. In this case, depicted in Figure 1.a, there is a unique equilibrium with $\eta<\eta^{*}$. Banks follow strategy 1 .

Case 2. When the function $\mathrm{E}$ has the configuration depicted in Figure 1.b, there is a unique equilibrium in which $\eta>\eta *$ Banks follow strategy 2 .

Case 3. If $\mathrm{E}$ has the configuration depicted in Figure 1.c, there are two equilibria. ${ }^{20}$ One has $\eta=$ $\eta_{1}<\eta^{*} ;$ the other has $\eta=\eta_{2}>\eta^{*}$.

Since $Q(\eta ; \gamma, \lambda)=\eta(1-\tau) /(1+\mathrm{t})$ holds in equilibrium, if there are multiple equilibria both active banks and depositors have the same welfare ranking of the two equilibria. It is not unambiguous, in general, which equilibrium banks and depositors might prefer, although below we present examples in which they prefer the equilibrium with $\eta<\eta^{*}$. Borrowers might also prefer either equilibrium. We present examples below in which they too prefer equilibria with $\eta<\eta^{*}$. Hence it is possible that this economy has multiple equilibria which can be Pareto ranked.

We now turn our attention to two issues: (a) showing that an equilibrium exists, in general, and (b) describing conditions under which multiple equilibria can be observed. 


\section{E. Existence and Multiplicity of Equilibrium}

Our previous discussion implies that there exists an equilibrium with $\eta<\eta^{*}$ if

$$
\left(1+\mathrm{q}_{1}\right)\left[\eta^{*}-\int_{0}^{\eta^{*}} \mathrm{G}(z) \mathrm{d} z\right]-\left(\gamma / \mathrm{q}_{1}\right) \mathrm{G}\left(\eta^{*}\right)>\bar{\pi}_{1}
$$

Similarly, there exists an equilibrium with $\eta>\eta^{*}$ if

$$
\bar{\pi}_{2}>\left(1+\mathrm{q}_{2}\right)\left[\eta^{*}-\int_{0}^{\eta^{*}} \mathrm{~F}(z) \mathrm{d} z\right]-\left(\gamma / \mathrm{q}_{2}\right) \mathrm{F}\left(\eta^{*}\right) .
$$

We now establish the following result.

Proposition 2. At least one of the conditions (24) and (25) holds.

The proof of proposition 2 appears in appendix A. The proposition establishes that $\mathrm{E}(\eta ; \gamma, \lambda)=0$ has at least one solution. Parenthetically, we might note that it is easy to show that that solution has $\eta<$ $\max \left\{\hat{\mathrm{X}}_{1}, \hat{\mathrm{X}}_{2}\right\}$. It is then immediate that loan rates exceed deposit rates, so long as deposit insurance premia are nonnegative.

It remains to establish conditions under which multiple equilibria can be observed. The following proposition gives one sufficient condition.

PROPOSITION 3. Suppose that $1>\gamma \mathrm{f}(0) / \mathrm{q}_{2}>\gamma \mathrm{g}(0) / \mathrm{q}_{1}$ holds. Then there is a nonempty set of values $\left(\bar{\pi}_{1}\right.$, $\bar{\pi}_{2}$ ) that imply the existence of two equilibria. 
Proposition 3 is proved in appendix B.

It will be apparent from an examination of appendix B that the existence of multiple equilibria is guaranteed only in a region where $\bar{\pi}_{1}$ and $\bar{\pi}_{2}$ ( and hence $\eta_{1}$ and $\eta_{2}$ ) are small. It is therefore important to note that the proof of proposition 3 focuses only on sufficient conditions for the existence of multiple equilibria. It is straightforward to produce examples where multiple equilibria are observed, and where both equilibria display "reasonable" values of interest rates on loans and deposits. We now provide such an example.

Example 1. For this example and those that follow we set $\mathrm{f}(z) \equiv 1 / \bar{z} \forall \mathrm{z} \in[0, \bar{z}]$, and we set

$$
\mathrm{g}(z)=\begin{aligned}
& (1-\varepsilon) / \bar{z} ; z \leq \bar{z} / 2 \\
& (1+\varepsilon) / \bar{z} ; z>\bar{z} / 2
\end{aligned}
$$

For this example, $\varepsilon=0.01$ and $\bar{z}=3$ hold. In addition, we set $\mathrm{q}_{1}=20, \mathrm{q}_{2}=10, \delta=1, \gamma=\lambda=0.5$, and $\mathrm{t}=$ 0. Thus the FDIC charges no premiums for deposit insurance (clearly implying that deposit insurance must be subsidized). Finally, we set $\alpha=0.1, \beta=0.2$, and $\bar{u}=4.59$.

For this example $\hat{\mathrm{x}}_{1}=1.2522$ and $\hat{\mathrm{x}}_{2}=1.3405$. The example has the property that the constraint (8) binds in the problem (P.2), but the analogous constraint does not bind in the problem (P.1). Thus, if there are multiple equilibria, borrowers unambiguously prefer the equilibrium where $\eta<\eta^{*}$ (banks follow strategy 1). Finally, we note that $\mathrm{p}\left(\hat{\mathrm{x}}_{1}\right)=0.3151$.

For this example there is an equilibrium with $\eta=r=1.146$. At this interest rate, a bank's net expected profit under strategy 1 is 0.9198 . A bank's net expected profit under strategy 2 is 0.9157 . Thus, $1.146<\eta^{*}$ holds, and there is indeed an equilibrium where banks follow strategy 1 . In this equilibrium $\tau=$ 0.1973. There is also an equilibrium in which $\eta=r=1.1471$. At this interest rate a bank's net expected profit under strategy 1 is 0.9058 . A bank's net expected profit under strategy 2 is .9087 . In other words 
$1.1471>\eta^{*}$, and there is also an equilibrium in which banks follow strategy 2 . In this second equilibrium $\tau$ $=0.2078$.

Notice that the low interest rate equilibrium is preferred by all agents; bankers, depositors, and borrowers alike. Thus, as we mentioned previously, it is quite possible that not only do multiple equilibria exist, but that the equilibria can be Pareto ranked as well. Notice also that both equilibria have net real rates of interest on loans and deposits that are positive. This serves to emphasize that the proof of proposition 3 provides conditions that are sufficient, but far from necessary, in order for multiple equilibria to be observed. Finally, we point out that the high-interest-rate equilibrium also has a high loss rate for the FDIC.

\section{F. Some Consequences of Multiple Equilibria}

There are at least two interpretations that can be given to the existence of multiple equilibria. For both it is convenient to think of an economy where the situation we have described is repeated over and over, possibly (but not necessarily) in an overlapping generations context. ${ }^{21}$ Under one interpretation we can imagine two intrinsically identical closed economies. One of them has an equilibrium with $\eta<\eta^{*}$ at all dates; the other has an equilibrium with $\eta>\eta^{*}$ at all dates. The former economy would necessarily have a larger volume of aggregate credit extension $\left[\theta \alpha=(1-\alpha) q_{1} /\left(1+q_{1}\right)\right]$ than the latter $[\theta \alpha=(1-$ a) $\mathrm{q}_{2} /\left(1+\mathrm{q}_{2}\right)$ ], and a lower incidence of bank failures. In addition, if $\hat{\mathrm{x}}_{1} \leq \hat{\mathrm{x}}_{2}$ holds (as it does in example 1), the former economy would have a lower incidence of loan defaults. And, in the context of example 1, all agents would enjoy higher welfare in the first economy. In short, when two intrinsically identical economies experience permanently different equilibria, it can easily be the case that one of them is trapped with an unnecessarily inefficient financial system. This inefficiency could obviously have adverse real effects.

Alternatively, we can imagine a single economy where in some periods-possibly based on the realization of a sunspot variable (Cass and Shell, 1983) - the economy has an equilibrium with $\eta<\eta^{*}$, 
while in others it has an equilibrium with $\eta>\eta^{*}$. In periods with $\eta<\eta^{*}$, bank failure rates and borrower default rates will be low (if $\hat{\mathrm{x}}_{1} \leq \hat{\mathrm{x}}_{2}$ ) and potentially welfare will uniformly be high (as in example 1). In periods with $\eta>\eta^{*}$ bank failure rates and borrower default rates will be high (if $\hat{\mathrm{x}}_{1} \leq \hat{\mathrm{x}}_{2}$ ) and welfare may be low. In addition, as in example 1, the FDIC loss rate will be relatively high, if the FDIC exogenously sets its deposit insurance premia. In short, the economy will experience many of the symptoms of cyclical fluctuations, driven in this case by random sunspot fluctuations between multiple equilibria.

To summarize, when multiple equilibria are observed this is consistent with the occurrence of something analogous to a development trap. It is also consistent with existence of cyclical fluctuations arising from a sunspot process that works through the financial system.

\section{G. Modifications Under Alternative FDIC Funding Schemes}

We now show how the analysis must be modified if lump-sum taxes to support the FDIC are levied on funded borrowers as well as on all bank depositors. Of course, in this case funded borrowers require $\mathrm{q}_{1}+\tau\left(\mathrm{q}_{2}+\tau\right)$ units of funds to invest $\mathrm{q}_{1}\left(\mathrm{q}_{2}\right)$ in a type $1(2)$ project, and to pay their taxes. In addition, as we showed in section II, strategy 1 (2) is optimal for banks if $r(1+t)=\eta<(>) \bar{\eta}(\tau)$. It follows that the expected net payoff of an active bank, denoted here by $Q(\eta, \tau)$, is given by

$$
\mathrm{Q}(\eta, \tau)=\begin{aligned}
& \bar{\pi}_{1}-\mathrm{q}_{1} \Phi_{1}\left[\eta\left(\mathrm{q}_{1}+\tau\right) / \mathrm{q}_{1}\right] ; \eta \leq \bar{\eta}(\tau) \\
& \bar{\pi}_{2}-\mathrm{q}_{2} \Phi_{2}\left[\eta\left(\mathrm{q}_{2}+\tau\right) / \mathrm{q}_{2}\right] ; \eta \geq \bar{\eta}(\tau) .
\end{aligned}
$$

And, it is easy to verify that potential bankers are indifferent between owning banks and being bank depositors if (17) holds, as before.

In analogy with our previous notation, let $q(\eta, \tau)$ denote the optimal net of tax loan quantity offered by an active bank. Then clearly 


$$
\mathrm{q}(\eta, \tau)=\begin{aligned}
& \mathrm{q}_{1} ; \eta<\bar{\eta}(\tau) \\
& \mathrm{q}_{2} ; \eta>\bar{\eta}(\tau) .
\end{aligned}
$$

It is then easy to see that sources and uses of funds are equal if the fraction of funded borrowers, $\theta$, satisfies

$$
\theta=(1-\alpha) / \alpha\{1+q(\eta, \tau)]
$$

Finally, the FDIC collects $\alpha \theta t[q(\eta, \tau)+\tau]$ in deposit insurance premia in period 1 , and it collects $(1-\alpha) \tau$ in lump-sum taxes. These revenues are deposited in banks, earning the gross return $\mathrm{r}$. Hence second period FDIC income from these sources is

$$
\begin{aligned}
& \mathrm{r}\{\alpha \theta \mathrm{t}[\mathrm{q}(\eta, \tau)+\tau]+(1-\alpha) \tau\}=(1-\alpha) \eta[(\mathrm{t}+\tau) /(1+\mathrm{t})] \mathrm{q}(\eta, \tau) /[1+\mathrm{q}(\eta, \tau)] \\
& +(1-\alpha) \eta \tau /[1+\mathrm{q}(\eta, \tau)]
\end{aligned}
$$

This differs from our previous expression only in the second term on the right-hand side; this term reflects the lump-sum taxes collected from funded borrowers.

If $\eta<\bar{\eta}(\tau)$ holds (so that banks follow strategy 1), then in the second period the FDIC has ex post state verification costs of $\alpha \theta \gamma \mathrm{G}\left[\eta\left(\mathrm{q}_{1}+\tau\right) / \mathrm{q}_{1}\right]$, and its net obligations to depositors equal $\alpha \theta\left\{\eta\left(\mathrm{q}_{1}+\right.\right.$ $\left.\tau)-\mathrm{q}_{1} \Phi_{1}\left[\eta\left(\mathrm{q}_{1}+\tau\right) / \mathrm{q}_{1}\right]\right\}$. On the other hand, if $\eta>\bar{\eta}(\tau)$ holds (so that banks follow strategy 2 ), the FDIC's second period verification costs are $\alpha \theta \gamma \mathrm{F}\left[\eta\left(\mathrm{q}_{2}+\tau\right) / \mathrm{q}_{2}\right]$, and its net obligations to depositors are $\alpha \theta\left\{\eta\left(\mathrm{q}_{2}+\tau\right)-\mathrm{q}_{2} \Phi_{2}\left[\eta\left(\mathrm{q}_{2}+\tau\right) / \mathrm{q}_{2}\right]\right\}$. Using (28) to eliminate $\theta$ from these expressions, it is straightforward to show that the FDIC break-even requirement is 
(29.a) $\left[\eta\left(\mathrm{q}_{1}+\tau\right) / \mathrm{q}_{1}\right]-\Phi_{1}\left[\eta\left(\mathrm{q}_{1}+\tau\right) / \mathrm{q}_{1}\right]+\left(\gamma / \mathrm{q}_{1}\right) \mathrm{G}\left[\eta\left(\mathrm{q}_{1}+\tau\right) / \mathrm{q}_{1}\right]=\left[\eta\left(\mathrm{q}_{1}+\tau\right) / \mathrm{q}_{1}\right]-\eta(1-\tau) /(1+\mathrm{t})$,

if $\eta<\bar{\eta}(\tau)$, and is

$$
\left[\eta\left(\mathrm{q}_{2}+\tau\right) / \mathrm{q}_{2}\right]-\Phi_{2}\left[\eta\left(\mathrm{q}_{2}+\tau\right) / \mathrm{q}_{2}\right]+\left(\gamma / \mathrm{q}_{2}\right) \mathrm{F}\left[\eta\left(\mathrm{q}_{2}+\tau\right) / \mathrm{q}_{2}\right]=\left[\eta\left(\mathrm{q}_{2}+\tau\right) / \mathrm{q}_{2}\right]-\eta(1-\tau) /(1+\mathrm{t})
$$

if $\eta>\bar{\eta}(\tau)$. Equations (17) and (29) then determine the equilibrium values of $\eta=\mathrm{r}(1+\mathrm{t})$ and $\mathrm{t}$, if the FDIC exogenously sets its loss rate $\tau$.

A comparison of (22) with (29) will indicate that the equilibrium conditions here are identical to the equilibrium conditions in section $D$, except that here $\eta[q(\eta, \tau)+\tau] / q(\eta, \tau)$ plays the role that $\eta$ played in section D. Thus the taxation of funded borrowers introduces only one new "wrinkle" into the analysis: here strategy $1(2)$ is optimal for banks if $\eta<(>) \bar{\eta}(\tau)$. Thus here the magnitude of the lump-sum tax can affect the equilibrium lending strategy of banks.

To determine an equilibrium, we may proceed as follows. To begin, define $\mu_{1} \equiv \eta\left(\mathrm{q}_{1}+\tau\right) / \mathrm{q}_{1}$ and $\mu_{2} \equiv \eta\left(\mathrm{q}_{2}+\tau\right) / \mathrm{q}_{2}$. Then we find the smallest solution of

$$
\bar{\pi}_{1}-\mathrm{q}_{1} \Phi_{1}\left(\mu_{1}\right)=\Phi_{1}\left(\mu_{1}\right)-\left(\gamma / \mathrm{q}_{1}\right) \mathrm{G}\left(\mu_{1}\right)
$$

Given this value $\mu_{1}$, and given the FDIC loss parameter $\tau$, (29.a) then determines t. If the value $\mu_{1}$ obtained in this way satisfies $\mu_{1}<\bar{\eta}(\tau)$, then there is an equilibrium in which banks follow strategy 1 . Similarly, we find the smallest solution of

$$
\bar{\pi}_{2}-\mathrm{q}_{2} \Phi_{2}\left(\mu_{2}\right)=\Phi_{2}\left(\mu_{2}\right)-\left(\gamma / \mathrm{q}_{2}\right) \mathrm{F}\left(\mu_{2}\right)
$$


Given this value $\mu_{2}$ and $\tau$, (29.b) then yields a value for t. If the value $\mu_{2}$ satisfies $\mu_{2}>\bar{\eta}(\tau)$, then there is an equilibrium in which banks follow strategy 2.

As before, there is considerable scope for more than one equilibrium to exist. And here, given the dependence of $\bar{\eta}$ on $\tau$, the potential for multiple equilibria to be observed does depend on the policy choices made by the FDIC. We now illustrate this point in the context of some examples.

\section{Examples}

In this section we provide some numerical examples intended to illustrate various points. All of the examples are computed under the assumption that depositors and funded borrowers pay any lumpsum taxes required to support the FDIC. This assumption is made, in part, because we want to illustrate how changes in FDIC losses may affect equilibria. If only depositors paid lump-sum taxes, we know that no aspect of FDIC policy would matter for any equilibrium values that determine agents' welfare levels.

We consider three sets of examples. The first shows how changes in FDIC losses $(\tau)$ affect various dimensions of an equilibrium, or of the set of equilibria. The second illustrates how shifts in the distribution of project returns - which can be interpreted as real shocks - affect equilibria. The third focuses on how changes in ex post monitoring costs — which can be regarded as secular changes in the severity of the CSV friction examined here-affect equilibria.

\section{The Effects of Varying FDIC Losses}

The economy is identical to that of example 1 with three exceptions. First, as noted previously, all depositors and all funded borrowers pay any lump-sum taxes intended to cover FDIC losses. Second, since we want to illustrate the consequences of varying FDIC losses, we assume that the FDIC chooses $\tau$.

Thus the deposit insurance premium $t$ is endogenous. Third, all values of non-policy parameters are identical to example 1 except that here $\bar{u}=4.55$.

Table 1 reports the consequences of varying FDIC losses (discounted to the present) from $\tau=0$ to $\tau=0.2$. As indicated there, for low values of $\tau$ there is a unique equilibrium in which banks follow 
strategy 2. For values of $\tau \leq 0.1$, increases in $\tau$ causes reductions in the rate of interest on loans $\left(\mathrm{x}_{2}\right)$, increases in the rate of interest on deposits, and naturally reductions in the deposit insurance premium. Of course, as we have shown, none of these changes have any welfare consequences so long as banks continue to follow strategy 2.

For $\tau=0.1$, but not for $\tau=0.05$ or $\tau=0.15$, there are two equilibria. The expected utility of banks and depositors is $\mathrm{r}(1-\tau)$ : therefore all of these agents prefer the equilibrium where banks follow strategy 1 . In addition, when banks follow strategy 2 , the constraint (8) binds in the problem (P.2). The analogous constraint does not bind in the problem (P.1). Thus borrowers are also better off in the equilibrium where banks follow strategy 1. Again we have two Pareto ranked equilibria.

For $\tau \geq 0.15$, there is a single equilibrium in which banks follow strategy 1 . In this range increases in $\tau$ continue to increase rates of interest on deposits and to reduce rates of interest on loans. But once again this is irrelevant from a welfare perspective.

This example illustrates an extremely important point: all agents are better off in an equilibrium where banks follow strategy 1 than they are in an equilibrium where banks follow strategy 2 . In order for the former equilibrium to exist it is necessary that $\tau$ (the discounted present value of FDIC losses) be sufficiently high. Thus there is no presumption whatsoever that it is desirable for FDIC losses to be low. Moreover, when $\tau=0$ there is no subsidy from the FDIC to banks: deposit insurance is priced "fairly." Here this leads to a "bad" outcome. There is a unique equilibrium, but a Pareto superior (and unique) equilibrium could be attained by increasing FDIC losses. Thus there is also no presumption that it is desirable for the FDIC to price deposit insurance fairly.

\section{Shifts in the Distributions of Returns}

We now consider the same economy, but with two changes. First, $\tau$ is fixed at 0.1 . Second, we allow $\bar{z}$ to vary between 2.9 and 3.1. Increases in $\bar{z}$ increase both the mean return and the variance of returns on projects of both types. However, they leave $\hat{z}_{1} / \hat{z}_{2}$ unchanged. Similarly, if $\sigma_{1}^{2}\left(\sigma_{2}^{2}\right)$ is the 
variance of returns on type 1 (2) projects, increases in $\bar{z}$ leave $\sigma_{1}^{2} / \sigma_{2}^{2}$ unchanged. Increases or reductions in $\bar{z}$ can be regarded as real shocks that shift the distribution of "output" in period 2.

Table 2 shows how variations in $\bar{z}$ affect various aspects of an equilibrium. As is evident from the table, for low values of $\bar{z}$ there is a unique equilibrium in which banks follow strategy 2. Within such equilibria increases in $\bar{z}$ result in higher rates of interest on loans and deposits. With $\tau$ fixed, higher rates of interest on deposits reflect higher levels of depositor (and banker) expected utility. For borrowers our example has the feature that the constraint (8) always binds in the problem (P.2): thus borrower welfare is independent of $\bar{z}$.

For $\bar{z}=3$ there are again two Pareto ranked equilibria. (This is identical to the previous example with $\tau=0.1$ ) For higher values of $\bar{z}$ there is a unique equilibrium where banks follow strategy 1 . Here higher deposit rates of interest as $\bar{z}$ rises again translate into higher levels of (expected) utility for banks and borrowers. And, it is easy to verify that for $\bar{z} \geq 3.05$, higher values of $\bar{z}$ also result in higher levels of borrower expected utility.

If we consider a repeated version of our model where a value of $\bar{z}$ is drawn randomly in each period, high values of $\bar{z}$ result in a unique equilibrium where banks follow strategy 1 . The higher $\bar{z}$, the higher the expected utility of all agents. Low values of $\bar{z}$ lead to a unique equilibrium where banks follow strategy 2. The higher $\bar{z}$, the higher the expected utility of bankers and depositors.

For intermediate values of $\bar{z}$ multiple equilibria exist. Thus real shocks interact with the scope for sunspot equilibria to exist. For "very low" values of $\bar{z}$-representing a relatively severe recessionthere is only one equilibrium. Similarly for "very high" values of $\bar{z}$-representing a relatively large scale expansion-there is a unique equilibrium. For intermediate values of $\bar{z}$ the economy can experience endogenously enhanced volatility since sunspot equilibria can be observed.

\section{Changes in Ex Post Verification Costs}

The economy is as in the previous examples, except that $\tau$ is fixed at 0.1 , and $\bar{z}$ is fixed at 3.0. We now consider the consequences of allowing the ex post verification cost to vary between 0.3 and 0.7 
Table 3 reports various equilibrium values for ex post monitoring costs in this range. As is apparent from the table, for low monitoring costs there is a unique equilibrium in which banks follow strategy 2. For this example, as for the others reported previously, when banks follow strategy 2 all funded borrowers obtain the expected utility level $\overline{\mathrm{u}}$. Thus increases in ex post verification costs affect neither borrower welfare, nor the rate of interest on loans, $\mathrm{x}_{2}$. However, as monitoring costs rise so too do the FDIC's costs of operation: this is reflected in the necessity of raising the deposit insurance premium along with $\gamma$ in order to keep FDIC losses constant.

Lender utility is, of course, simply a monotonic function of $r(1-\tau)$, as is the expected utility of potential bankers. Thus as $\gamma$ rises from 0.3 to 0.4 , the welfare of everyone other than borrowers falls.

When $\gamma=0.5$, there are two equilibria. When banks follow strategy 1 , borrower expected utility exceeds $\overline{\mathrm{u}}$. Thus borrowers prefer that equilibrium. So too do lenders, since $\mathrm{r}(1-\tau)$ is higher under "the strategy 1" than under "the strategy 2" equilibrium. As before, there are two Pareto ranked equilibria.

As $\gamma$ increases further, from 0.5 to 0.6 , there cease to be two equilibria. Instead there is a unique equilibrium where banks follow strategy 1. And, beyond that point, incremental increases in $\gamma$ have the effect of reducing the rate of interest on both loans and deposits, and, of course, they require the FDIC to raise the deposit insurance premium. The decline in the rate of interest on loans raises the welfare of funded borrowers; the decline in the rate of interest on deposits reduces the welfare of lenders and potential bankers. Thus, for monitoring costs consistent with an equilibrium where banks follow strategy 1 , increases in monitoring costs result in a redistribution that favors borrowers, as well as a higher deadweight loss due to the CSV problem.

It is clear from Table 3 that all agents would prefer to have $\gamma=0.5$ and be in the "strategy 1 equilibrium", than to have $\gamma=0.4$, which results in a (unique) "strategy 2 equilibrium". This illustrates another important point. Reductions in ex post verification costs increase the technical efficiency of the financial system. But, if they cause banks to switch from strategy 1 to strategy 2 , such cost reductions may reduce the welfare of all agents. This is a caution against jumping to the conclusion that reductions 
in transactions costs are unambiguously "a good thing"22. Moreover, bank failure rates are unambiguously higher when $\gamma=0.4$ than they are in "the strategy 1 equilibrium" when $\gamma=0.5$. Thus an outside observer might see a reduction in transactions costs leading to a Pareto inferior allocation of resources, and a higher bank failure rate. Such an observer might also see the same reduction leading to the existence of smaller banks following a less sophisticated strategy for the control of moral hazard problems in lending.

One might think of a reduction in monitoring costs as being a natural concomitant of economic development. This example illustrates that such development need not render problems of moral hazard in banking any less significant.

\section{Conclusions}

We have presented a model which was designed to undertake a very simple general equilibrium analysis of the consequences of deposit insurance programs, the way in which they are priced, and the way in which they fund revenue shortfalls. Assuming that deposits are 100 percent insured (or that the government will not allow certain banks to fail), and assuming flat rate pricing of deposit insurance, we

have shown that the following is a central issue: how will the government make up any FDIC losses? Under one scheme for making up these losses we have shown that FDIC policy is irrelevant: it does not matter what premium is charged, nor does it matter how big FDIC losses are. Neither dimension of FDIC policy affects the set of equilibria, or the welfare of agents within a given equilibrium. Under another, not very different method for making up these losses, all that matters is the magnitude of the losses. And, there is no presumption that small losses are "good", either from a welfare perspective, or from the perspective of multiplicity of equilibria.

We have also shown that multiple equilibria can easily be observed and that, under some circumstances, these equilibria can be Pareto ranked. This multiplicity of equilibria can lead some economies to be "trapped" in equilibria with inefficient financial systems. And, in a repeated version of 
our model, it can give rise to business cycles driven by "sunspots." In recessions (expansions), the financial system will function relatively badly (well), as we observe in practice. Finally, if the FDIC makes up losses by taxing funded borrowers as well as savers, the magnitude of FDIC losses can affect the scope for sunspot equilibria or low level "traps" to be observed.

Admittedly these results have been derived in the context of a very simple model in which all agents make very simple decisions. It will be interesting to analyze in future work how sensitive some of our results are to various simplifying assumptions. But here we emphasize that our analysis provides counterexamples to the following kinds of propositions. (1) Actuarially fair pricing of deposit insurance is always desirable. (2) Implicit FDIC subsidization of banks through deposit insurance is always undesirable. (3) "Large" FDIC losses are necessarily symptomatic of a poorly designed deposit insurance system. The fact that our counterexamples to these propositions are simple does not negate the fact that they are counterexamples.

There are several extensions of the analysis that would be of interest. For instance, it would be quite possible to introduce some heterogeneity into the model so that there are large and small banks that also have different probabilities of failure [see Boyd, Chang and Smith (1998)]. In this context we could investigate the consequences of risk-based insurance premia. And we could investigate the consequences of allowing for coinsurance and nonlinear pricing of deposit insurance with or without heterogeneity. Perhaps the answers to some of our questions will differ as we move away from complete insurance of deposits (or "too big to fail") or from flat-rate deposit insurance premia. Nonetheless, we believe that our results do illustrate the importance of analyzing deposit insurance in a general equilibrium context. 


\section{Appendix}

\section{A. Proof of PROPOSITION 2}

Suppose to the contrary that (24) and (25) both fail to hold. Then it follows that

$$
\begin{array}{ll}
\text { (A.1) } & \bar{\pi}_{1}-\bar{\pi}_{2} \geq\left(\mathrm{q}_{1}-\mathrm{q}_{2}\right) \eta^{*}-\mathrm{q}_{1} \int_{0}^{\eta^{*}}\left[\mathrm{G}(\mathrm{z})-\left(\mathrm{q}_{2} / \mathrm{q}_{1}\right) \mathrm{F}(z)\right] \mathrm{d} z+\int_{0}^{\eta^{*}}[\mathrm{~F}(z)-\mathrm{G}(z)] \mathrm{d} z \\
& +\gamma\left\{\left[\mathrm{F}\left(\eta^{*}\right) / \mathrm{q}_{2}\right]-\left[\mathrm{G}\left(\eta^{*}\right) / \mathrm{q}_{1}\right]\right\}
\end{array}
$$

But, since $\mathrm{F}(z) \geq \mathrm{G}(z)$, with strict inequality for some $z$, (A.1) contradicts the definition of $\eta^{*}$.

\section{B. Proof of PROPOSITION 3}

There exist two equilibria if both (24) and (25) hold simultaneously. We establish the proposition by showing that its hypothesis implies the existence of a nonempty set of pairs $\left(\bar{\pi}_{1}, \bar{\pi}_{2}\right)$ such that (24) and (25) both hold. Before doing so, we note that $\bar{\pi}_{1}$ and $\bar{\pi}_{2}$ depend only on parameters, and that they depend on parameters like $\gamma$ and $\lambda$. Hence we can always make $\bar{\pi}_{1}$ and $\bar{\pi}_{2}$ as small as desired, and in such a way that $\bar{\pi}_{1}>\bar{\pi}_{2}$ holds.

Define the functions $\mathrm{H}_{1}(\eta)$ and $\mathrm{H}_{2}(\eta)$ by

(A.2) $\mathrm{H}_{1}(\eta) \equiv \eta-\int_{0}^{\eta} \mathrm{G}(z) \mathrm{d} z-\left[\gamma / \mathrm{q}_{1}\left(1+\mathrm{q}_{1}\right)\right] \mathrm{G}(\eta)$

(A.3) $\mathrm{H}_{2}(\eta) \equiv \eta-\int_{0}^{\eta} \mathrm{F}(z) \mathrm{d} z-\left[\gamma / \mathrm{q}_{2}\left(1+\mathrm{q}_{2}\right)\right] \mathrm{F}(\eta)$. 
We observe that the hypothesis of the proposition implies that $\mathrm{H}_{1}^{\prime}(0)>0$ and $\mathrm{H}_{2}^{\prime}(0)>0$ hold. In addition, define the functions $\eta_{1}\left(\bar{\pi}_{1}\right)$ and $\eta_{2}\left(\bar{\pi}_{2}\right)$ to be the smallest solutions to

(A.4) $\mathrm{H}_{1}\left[\eta_{1}\left(\bar{\pi}_{1}\right)\right] \equiv \bar{\pi}_{1} /\left(1+\mathrm{q}_{1}\right)$

(A.5) $\mathrm{H}_{2}\left[\eta_{2}\left(\bar{\pi}_{2}\right)\right] \equiv \bar{\pi}_{2} /\left(1+\mathrm{q}_{2}\right)$,

respectively. Then the functions $\eta_{1}$ and $\eta_{2}$ are well-defined if $\bar{\pi}_{1}$ and $\bar{\pi}_{2}$ are not too large. Observe that $\eta_{1}\left(\bar{\pi}_{1}\right)\left[\eta_{2}\left(\bar{\pi}_{2}\right)\right]$ is a candidate equilibrium value of $\eta$ where banks follow strategy 1 (2). In particular, if $\eta_{1}\left(\bar{\pi}_{1}\right)<\eta^{*}\left[\eta_{2}\left(\bar{\pi}_{2}\right)>\eta^{*}\right]$, then there is an equilibrium where banks employ strategy 1 (2). For future reference we note that

(A.6) $\eta_{1}^{\prime}\left(\bar{\pi}_{1}\right)=\left\{\left(1+\mathrm{q}_{1}\right)\left[1-\mathrm{G}\left(\eta_{1}\right)\right]-\left(\gamma / \mathrm{q}_{1}\right) \mathrm{g}\left(\eta_{1}\right)\right\}^{-1}$,

(A.7) $\eta_{2}{ }^{\prime}\left(\bar{\pi}_{2}\right)=\left\{\left(1+\mathrm{q}_{2}\right)\left[1-\mathrm{F}\left(\eta_{2}\right)\right]-\left(\gamma / \mathrm{q}_{2}\right) \mathrm{f}\left(\eta_{2}\right)\right\}^{-1}$.

It follows from the definition of $\eta^{*}$ that $\eta_{1}\left(\bar{\pi}_{1}\right)<\eta^{*}$ holds iff

(A.8) $\mathrm{q}_{1}\left[\eta_{1}\left(\bar{\pi}_{1}\right)-\int_{0}^{\eta_{1}\left(\bar{\pi}_{1}\right)} \mathrm{G}(z) \mathrm{d} z\right]-\mathrm{q}_{2}\left[\eta_{1}\left(\bar{\pi}_{1}\right)-\int_{0}^{\eta_{1}\left(\bar{\pi}_{1}\right)} \mathrm{F}(z) \mathrm{d} z\right]<\bar{\pi}_{1}-\bar{\pi}_{2}$.

Similarly, $\eta_{2}\left(\bar{\pi}_{2}\right)>\eta *$ holds iff 
(A.9) $\mathrm{q}_{2}\left[\eta_{2}\left(\bar{\pi}_{2}\right)-\int_{0}^{\eta_{2}\left(\bar{\pi}_{2}\right)} \mathrm{G}(z) \mathrm{d} z\right]-\mathrm{q}_{2}\left[\eta_{2}\left(\bar{\pi}_{2}\right)-\int_{0}^{\eta_{2}\left(\bar{\pi}_{2}\right)} \mathrm{F}(z) \mathrm{d} z\right]>\bar{\pi}_{1}-\bar{\pi}_{2}$.

Now consider the equation

(A.10) $\bar{\pi}_{2}=\bar{\pi}_{1}-\mathrm{q}_{1}\left[\eta_{1}\left(\bar{\pi}_{1}\right)-\int_{0}^{\eta_{1}\left(\bar{\pi}_{1}\right)} \mathrm{G}(z) \mathrm{d} z\right]+\mathrm{q}_{2}\left[\eta_{1}\left(\bar{\pi}_{1}\right)-\int_{0}^{\eta_{1}\left(\bar{\pi}_{1}\right)} \mathrm{F}(z) \mathrm{d} z\right]$.

Equation (10) defines a locus that is depicted in Figure 2. Since $\eta_{1}(0)=0$, the locus defined by (A.10) passes through the origin. Its slope is given by

$$
\begin{array}{ll}
\text { (A.11) } & \mathrm{d} \bar{\pi}_{2} /\left.\mathrm{d} \bar{\pi}_{1}\right|_{(\mathrm{A} .10)}=1-\left\{\mathrm{q}_{1}\left[1-\mathrm{G}\left(\eta_{1}\right)\right]-\mathrm{q}_{2}\left[1-\mathrm{F}\left(\eta_{1}\right)\right]\right\}\left\{( 1 + \mathrm { q } _ { 1 } ) \left[1-\mathrm{G}\left(\eta_{1}\right)-\right.\right. \\
& \left.\left.\left(\gamma \mathrm{g}\left(\eta_{1}\right) / \mathrm{q}_{1}\left(1+\mathrm{q}_{1}\right)\right)\right]\right\}^{-1} .
\end{array}
$$

Its slope at the origin is

$$
\text { (A.12) } \mathrm{d} \bar{\pi}_{2} /\left.\mathrm{d} \bar{\pi}_{1}\right|_{(\mathrm{A} .10)}=1-\left(\mathrm{q}_{1}-\mathrm{q}_{2}\right) /\left(1+\mathrm{q}_{1}\right)\left\{1-\left[\gamma \mathrm{g}(0) / \mathrm{q}_{1}\left(1+\mathrm{q}_{1}\right)\right]\right\} \text {. }
$$

The hypothesis of the proposition implies that - at the origin - the locus defined by (A.10) is positively sloped. Note that $\left(\bar{\pi}_{1}, \bar{\pi}_{2}\right)$ pairs below the locus defined by equation (A.10) satisfy (A.8), and therefore imply the existence of an equilibrium with $\eta_{1}\left(\bar{\pi}_{1}\right)<\eta^{*}$.

To continue, consider the equation

(A.13) $\bar{\pi}_{1}=\bar{\pi}_{2}+\mathrm{q}_{1}\left[\eta_{2}\left(\bar{\pi}_{2}\right)-\int_{0}^{\eta_{2}\left(\bar{\pi}_{2}\right)} \mathrm{G}(z) \mathrm{d} z\right]-\mathrm{q}_{2}\left[\eta_{2}\left(\bar{\pi}_{2}\right)-\int_{0}^{\eta_{2}\left(\bar{\pi}_{2}\right)} \mathrm{F}(z) \mathrm{d} z\right]$ 
The locus defined by (A.13) is depicted in Figure 3. Again this locus passes through the origin, and its slope is equal to

$$
\begin{array}{cl}
\text { (A.14) } & \mathrm{d} \bar{\pi}_{2} /\left.\mathrm{d} \bar{\pi}_{1}\right|_{(\mathrm{A} .13)}=1-\left\{\mathrm{q}_{1}\left[1-\mathrm{G}\left(\eta_{2}\right)\right]-\mathrm{q}_{2}\left[1-\mathrm{F}\left(\eta_{2}\right)\right]\right\}\left\{( 1 + \mathrm { q } _ { 2 } ) \left[1-\mathrm{F}\left(\eta_{2}\right)-\right.\right. \\
& \left.\left.\left(\gamma \mathrm{f}\left(\eta_{2}\right) / \mathrm{q}_{2}\left(1+\mathrm{q}_{2}\right)\right)\right]+\mathrm{q}_{1}\left[1-\mathrm{G}\left(\eta_{2}\right)\right]-\mathrm{q}_{2}\left[1-\mathrm{F}\left(\eta_{2}\right)\right]\right\}^{-1} .
\end{array}
$$

Evaluating this slope at the origin gives

$$
\text { (A.15) } \mathrm{d} \bar{\pi}_{2} /\left.\mathrm{d} \bar{\pi}_{1}\right|_{(\text {A.13) }}=1-\left(\mathrm{q}_{1}-\mathrm{q}_{2}\right) /\left[1+\mathrm{q}_{1}-\left(\gamma \mathrm{f}(0) / \mathrm{q}_{2}\right)\right]
$$

The hypothesis of the proposition implies that the locus defined by (A.13) is positively sloped at the origin. And, it is easy to verify that $\left(\bar{\pi}_{1}, \bar{\pi}_{2}\right)$ pairs above the locus defined by (A.13) satisfy (A.9).

The preceding discussion implies that any pairs $\left(\bar{\pi}_{1}, \bar{\pi}_{2}\right)$ lying below the locus defined by (A.10) and above the locus defined by (A.13) belong to an economy with multiple equilibria. Clearly the set of such pairs is non-empty if the locus defined by (A.10) is more steeply sloped than the locus defined by (A.13) at the origin. This situation, in turn, obtains if the hypothesis of the proposition is satisfied. 


\section{Footnotes}

${ }^{1}$ In the last few years, there have been banking crises of major proportions in a striking number of countries. The list runs the gamut from developed nations such as Japan, to developing nations such as Mexico, South Korea, Thailand, and Indonesia. Transitional economies (such as Russia) have not been spared either.

${ }^{2}$ The Japanese Ministry of Finance stated in 1996 that none of the nation's 21 largest banks will be permitted to fail.

${ }^{3}$ The list of studies on deposit insurance systems is a long one and cannot be fully referenced here. There have been two seminal theoretical studies on this topic. One of these is Kareken and Wallace (1978), which investigates the moral hazard problem caused by deposit insurance in an ArrowDebreu complete markets framework. The other is Merton (1977) which shows how modern option pricing theory can be applied to deposit insurance pricing. A seminal empirical paper is Keeley (1990), which shows how bank charter values (reflecting banks' ability to earn monopoly rents) can at least partially offset the moral hazard problem due to deposit insurance.

${ }^{4}$ Although some have questioned the feasibility of such pricing: see Chan, Greenbaum and Thakor (1992) and the subsequent treatment of this issue by Freixas and Rochet (1996).

${ }^{5}$ There is a great variety of deposit insurance systems across different nations, with some offering virtually unlimited coverage, and some offering none at all. Germany, for example, insures all nonbank depositors up to 30 percent of a bank's capital; essentially, unlimited protection. Greece and Portugal, on the other hand, have no explicit deposit insurance schemes. The EC is adopting a common system by the end of 1999; under which deposits will be insured up to a maximum of about $\$ 25,000$, subject to a 10 percent coinsurance clause However, as a practical matter, even when 100 percent deposit insurance is not explicitly provided, it is implicitly provided when large banks are treated as "too big to fail." And, when a banking system is highly concentrated with a relatively small number of large banks, 
this policy effectively constitutes complete insurance coverage for the system. Such defacto system-wide coverage has figured prominently in recent banking problems around the globe (Hellmann, 1998).

Flat-rate insurance premiums have been levied historically in the U. S. The FDICIA legislation of 1991 allows for risk-based pricing. But, even now, flat-rate premia closely approximate reality, as almost all banks have been placed in the same (lowest) risk class.

${ }^{6}$ More standard "risk-shifting" moral hazard models (Jensen and Meckling 1976) do not allow for such a combination of entrepreneurial actions. In such "risk-shifting" models, portfolio allocations are distorted (for example, by an engineering mean-preserving spread of the asset return distribution) but there is no role for the other misallocations of funds. Ackerloff and Romer present a related analysis in the context of moral hazard in banking firms. In their model, the bank manager may respond to adverse incentives either by "looting" or by "risk-shifting", depending on parameters. Their study also contains a useful discussion of real-world manifestations of both forms of behavior.

${ }^{7}$ See, for instance, Gurley and Shaw (1955), McKinnon (1973), Shaw (1973), and Levine (1997).

${ }^{8}$ This "diversion of funds" formulation loosely follows Gertler and Rogoff (1990). Since $\delta \leq 1$, expenditures on "perks" do not generate greater utility than the receipt of an equivalent amount of income. We impose $\hat{z}_{2}>\delta$ so that the diversion of funds is socially inefficient.

${ }^{9}$ There would be only minor differences in the analysis if interim monitoring could not be done stochastically.

${ }^{10}$ Again this assumption is inessential to the analysis.

${ }^{11}$ This assumption is also common in models with informational asymmetries.

${ }^{12}$ For a comparison of various contractual forms in this context, see Boyd, Chang, and Smith (1998). Boyd and Smith (1994) show, within the context of a conventional CSV model, that the gains to stochastic state verification are small for realistic parameter values. Finally we note that from a technical perspective, it is simplest to have stochastic interim monitoring and nonstochastic ex post state verification. 
13 “One bank - one borrower" assumptions are not uncommon; see, for instance, John, John and Saunders (1994), Berlin, John, and Saunders (1996), or Santos (1996). We also note that the one bankone borrower assumption is made only for simplicity. In practice one might imagine a bank dealing with several borrowers concentrated in a single geographic area or industry so that investment returns received by its borrowers are correlated.

${ }^{14}$ The assumption of "one bank - one borrower" and the indivisibility of investment projects makes such a tax isomorphic to a flat rate tax on deposits. The specification in the text somewhat simplifies calculations.

${ }^{15}$ When credit is rationed the analysis of a general equilibrium is somewhat easier because loan rates can be determined without reference to other endogenous variables.

${ }^{16}$ In particular we assume that a lender can observe directly whether or not some project was undertaken. Of course the lender cannot directly observe which project was undertaken, except by observing this ex post through the process of interim monitoring.

${ }^{17}$ Of course this assumes that credit is rationed.

${ }^{18}$ All depositors (including potential bankers) pay a lump-sum tax to support the FDIC. Some of the savings of these agents is also used to pay deposit insurance premiums. However, the FDIC reinvests all the funds it obtains. Hence payments to the FDIC do not constitute "leakages" from the credit market. This is, in fact, the purpose of assuming that the FDIC redeposits its funds with banks.

${ }^{19}$ In general the function $E$ could shift either up or down at $\eta=\eta^{*}$. Multiple equilibria (case 3) are possible only if it shifts up at that point.

${ }^{20}$ Given the fact that $\mathrm{E}$ can be nonmonotonic in $\eta$ only at $\eta=\eta^{*}$, there can be at most two equilibria.

${ }^{21}$ In an overlapping generations context, gross real interest rates on deposits in excess of unityas are observed in example 1 - would justify our focus on a nonmonetary economy.

${ }^{22}$ A similar point is made by Bencivenga, Smith, and Starr $(1994,1996)$. 


\section{References}

Akerlof, George A., and Paul M. Romer. "Looting: The Economic Underworld of Bankruptcy for Profit.” Brookings Papers on Economic Activity (1993), 1-60.

Bencivenga, Valerie R., Bruce D. Smith, and Ross M. Starr. "Liquidity of Secondary Capital Markets, Capital Accumulation, and the Term Structure of Asset Yields.” Manuscript (1994).

Bencivenga, Valerie R., Bruce D. Smith, and Ross M. Starr. "Liquidity of Secondary Capital Markets: Allocative Efficiency and the Maturity Composition of the Capital Stock." Economic Theory 7 (1996), 19-50.

Berlin, Mitchell, Kose John, and Anthony Saunders. "Bank Equity Stakes in Borrowing Firms and Financial Distress.” Review of Financial Studies 9, (1996), 889-919.

Boyd, John H., Chun Chang, and Bruce D. Smith. "Moral Hazard Under Commercial and Universal Banking.” Journal of Money, Credit, and Banking 30 (1998), 426-468.

Boyd, John H., and Bruce D. Smith. "How Good Are Standard Debt Contracts? Stochastic versus Nonstochastic Monitoring in a Costly State Verification Environment.” Journal of Business 67 (1994), 539-61.

Cass, David, and Karl Shell. “Do Sunspots Matter?” Journal of Political Economy 91 (1983), 193-227.

Chan, Yuk-shee, Stuart Greenbaum, and Anjan Thakor. "Is Fairly Priced Deposit Insurance Possible?" Journal of Finance 47 (1992), 227-245.

Dewatripont, Mathias, and Jean Tirole. The Prudential Regulation of Banks. Cambridge, Mass.: MIT Press, 1994.

Diamond, Douglas. "Financial Intermediation and Delegated Monitoring." Review of Economic Studies 51 (1984), 393-414. 
Freixas, Xavier, and Jean-Charles Rochet. "Fairly Pricing of Deposit Insurance. Is it Possible? Yes Is If Desirable? No.” Working Paper, Institut D’Economie Industrielle (1996).

Gale, Douglas, and Martin Hellwig. "Incentive-Compatible Debt Contracts: The One-Period Problem." Review of Economic Studies 52 (1985), 647-63.

Gertler, Mark, and R. Glenn Hubbard. "Financial Factors in Business Fluctuations." In Financial Market Volatility. Federal Reserve Bank of Kansas City, 1988.

Gertler, Mark, and Kenneth Rogoff. "North-South Lending and Endogenous Domestic Capital Market Inefficiences.” Journal of Monetary Economics 26 (1990), 245-66.

Gorton, Gary, and Joseph G. Haubrich. "Bank Deregulation, Credit Markets, and the Control of Capital." Carnegie-Rochester Conference Series on Public Policy 26 (1987), 289-334.

Gurley, John G., and Edward S. Shaw. "Financial Aspects of Economic Development." American Economic Review 45 (1955), 15-38.

Hellmann, Thomas, Kevin Murdock and Joseph Stiglitz. "Liberalization, Moral Hazard in Banking, and Prudential Regulation: Are Capital Requirements Enough?” Working Paper. Stanford Univeristy (1998).

John, Kose, T. A. John, and Anthony Saunders. "Universal Banking and Firm Risk Taking.” Journal of Banking and Finance 18 (1994), 307-323.

Kareken, John H., and Neil Wallace. "Deposit Insurance and Bank Regulation: A Partial Equilibrium Exposition." Journal of Business 51 (July 1978), 413-38.

Keeley, Michael C. "Deposit Insurance, Risk, and Market Power in Banking." The American Economic Review (1990).

Levine, Ross. "Financial Development and Economic Growth: Views and Agenda." Journal of Economic Literature (1997).

McKinnon, Ronald I. Money and Capital in Economic Development. Washington, DC: Brookings Institute, 1973. 
Merton, Robert C. “An Analytical Derivation of the Cost of Deposit Insurance and Loan Guarantees: An Application of Modern Option Pricing Theory.” Journal of Banking and Finance 1 (June 1977), 3-11.

Santos, Joao. “Bank Capital and Equity Investment Regulations.” Manuscript (1996).

Saunders, Anthony. Financial Institutions Management: A Modern Perspective. New York: Irwin, 1997.

Shaw, Edward S. Financial Deepening in Economic Development. New York: Oxford University Press, 1973.

Townsend, Robert M. “Optimal Contracts and Competitive Markets with Costly State Verification.” Journal of Economic Theory 21 (1979), 265-93.

Williamson, Stephen D. "Costly Monitoring, Financial Intermediation, and Equilibrium Credit Rationing.” Journal of Monetary Economics 18 (1986), 159-79.

. “Costly Monitoring, Loan Contracts, and Equilibrium Credit Rationing.” Quarterly Journal of Economics 102 (1987), 135-45. 


\section{TABLE 1}

\begin{tabular}{|c|c|c|c|c|c|c|}
\hline \multirow[b]{2}{*}{$\tau$} & \multicolumn{3}{|c|}{ Equilibrium 1} & \multicolumn{3}{|c|}{ Equilibrium 2} \\
\hline & $\mathrm{x}_{1}$ & $\mathrm{r}$ & $\mathrm{t}$ & $\mathrm{x}_{2}$ & $\mathrm{r}$ & $\mathrm{t}$ \\
\hline 0 & - & - & - & 1.3477 & 0.9121 & 0.2639 \\
\hline 0.05 & - & - & - & 1.3410 & 0.9601 & 0.1947 \\
\hline 0.10 & 1.2460 & 1.0220 & 0.1157 & 1.3344 & 1.0135 & 0.1263 \\
\hline 0.15 & 1.2429 & 1.0822 & 0.0511 & - & - & - \\
\hline 0.20 & 1.2398 & 1.1498 & -0.0132 & - & - & - \\
\hline
\end{tabular}

Legend: $\quad$ Equilibrium 1 (2) refers to an equilibrium when banks follow strategy 1 (2). $\mathrm{A}$ - indicates that there is only one equilibrium for the relevant parameters. We observe that $\mathrm{x}_{\mathrm{i}}=\hat{\mathrm{x}}_{\mathrm{i}} \mathrm{q}_{\mathrm{i}} /\left(\mathrm{q}_{\mathrm{i}}+\tau\right) ; \mathrm{i}=1,2$.

TABLE 2

Equilibrium 1

$\bar{z}$

2.90

2.95

3.00

3.05

3.10
$\mathrm{X}_{1}$

$-$

-

1.2460

1.2762

1.3109 r
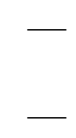

1.0220

1.0505

1.0794 $\mathrm{t}$

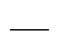

-

0.1157

0.1192

0.1229

\begin{tabular}{ccc}
\hline & Equilibrium 2 \\
\hline $\mathrm{x}_{2}$ & $\mathrm{r}$ & $\mathrm{t}$ \\
1.2629 & 0.9638 & 0.1215 \\
1.2986 & 0.9886 & 0.1239 \\
1.3344 & 1.0135 & 0.1263 \\
- & - & - \\
- & - & -
\end{tabular}


TABLE 3

\begin{tabular}{|c|c|c|c|c|c|c|}
\hline \multirow[b]{2}{*}{$\gamma$} & \multicolumn{3}{|c|}{ Equilibrium 1} & \multicolumn{3}{|c|}{ Equilibrium 2} \\
\hline & $\mathrm{x}_{1}$ & $\mathrm{r}$ & $\mathrm{t}$ & $\mathrm{x}_{2}$ & $\mathrm{r}$ & $\mathrm{t}$ \\
\hline 0.3 & - & - & - & 1.3344 & 1.0302 & 0.1197 \\
\hline 0.4 & - & - & - & 1.3344 & 1.0218 & 0.1230 \\
\hline 0.5 & 1.2460 & 1.0220 & 0.1157 & 1.3344 & 1.0135 & 0.1263 \\
\hline 0.6 & 1.2458 & 1.0179 & 0.1173 & - & - & - \\
\hline 0.7 & 1.2456 & 1.0137 & 0.1189 & - & - & - \\
\hline
\end{tabular}


Figure la

A Unique Equilibrium (Strategy 1 Optimal)

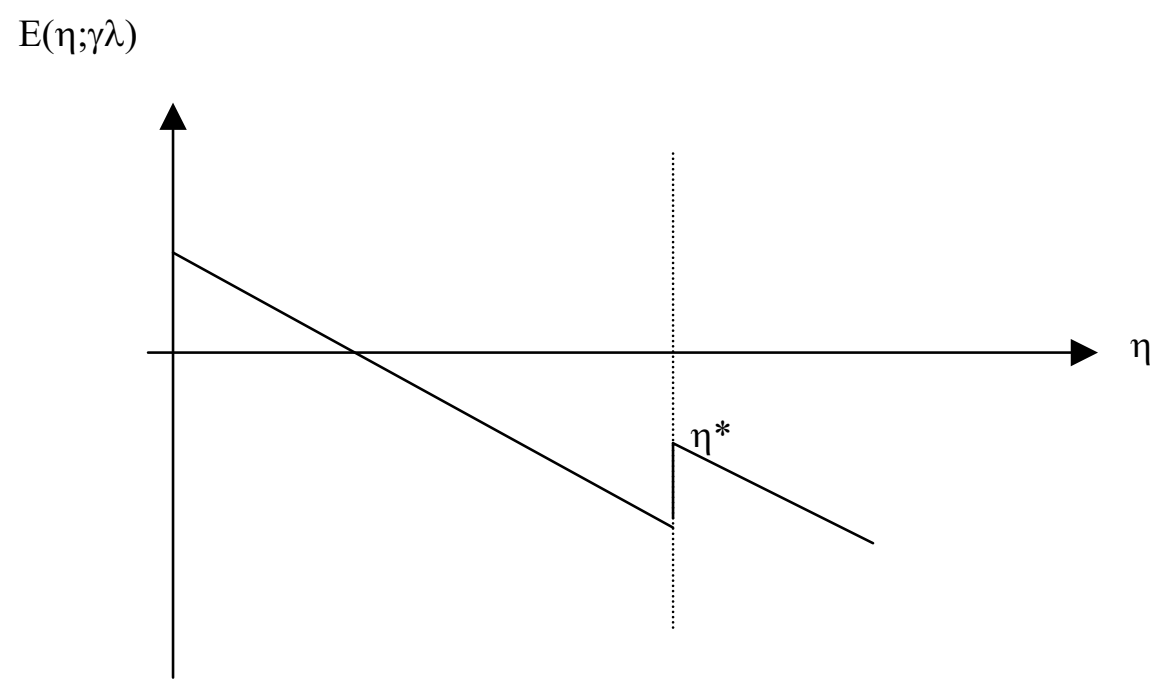

Figure 1.b

A Unique Equilibrium (Strategy 2 Optimal)

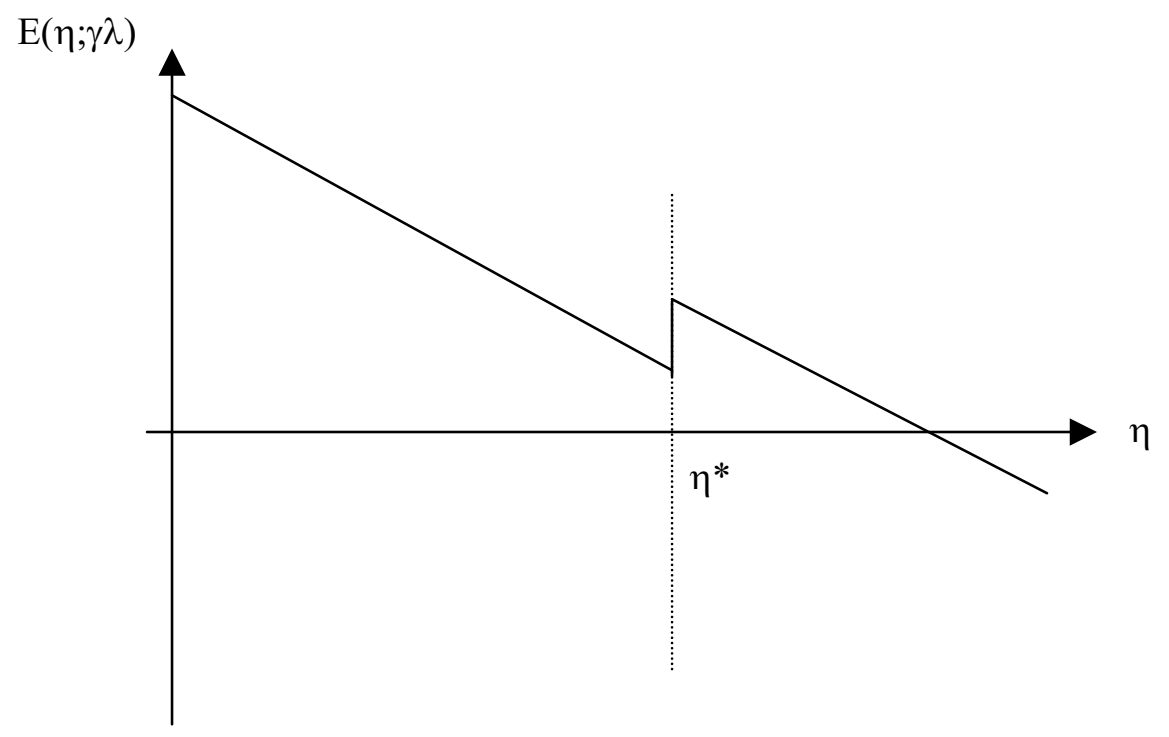


Figure 1.C

Multiple Equilibria

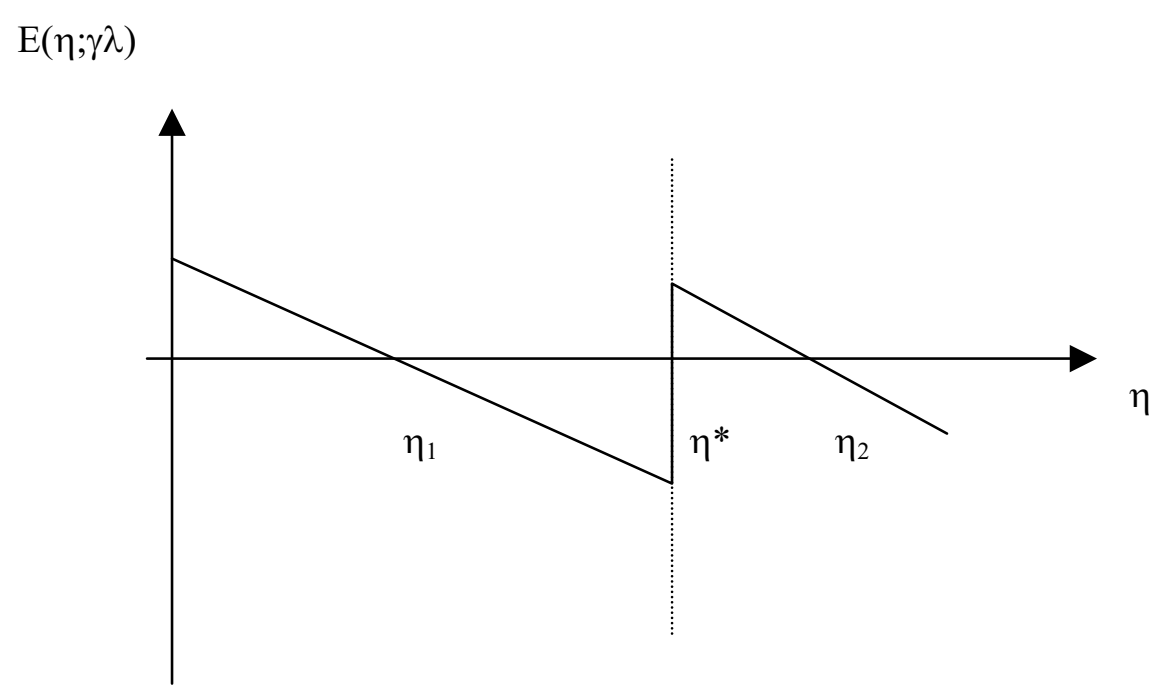

Figure 2

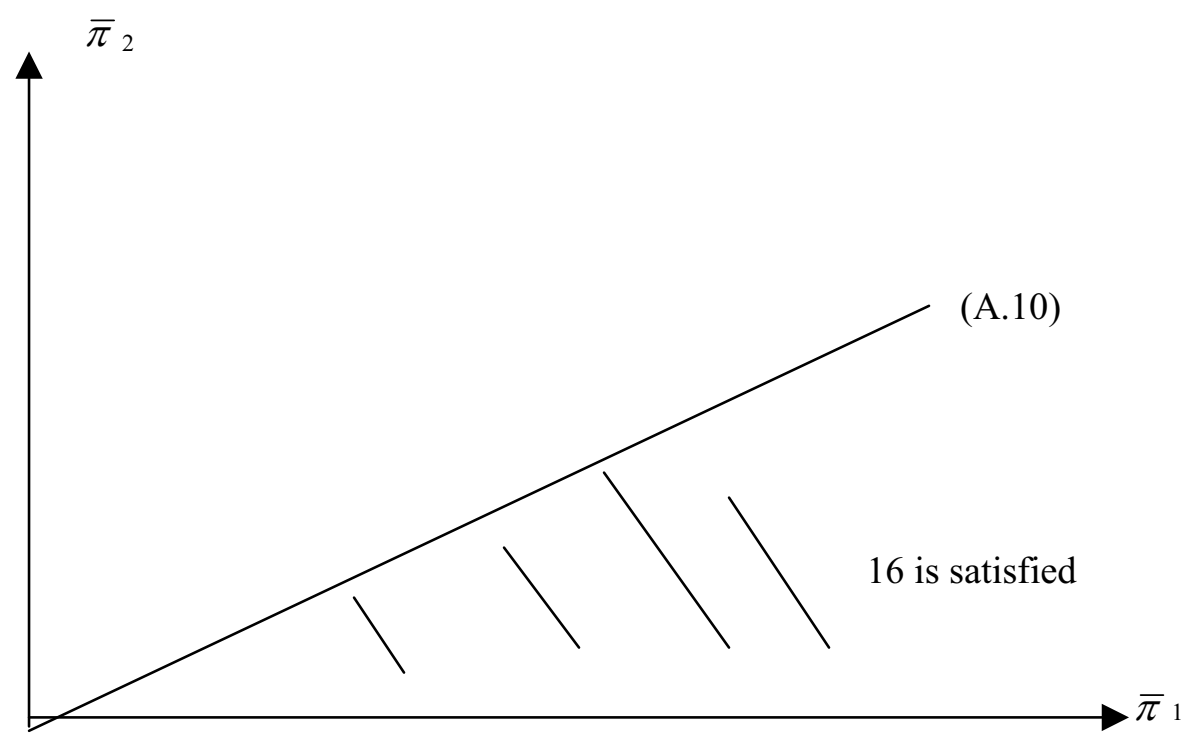


Figure 3

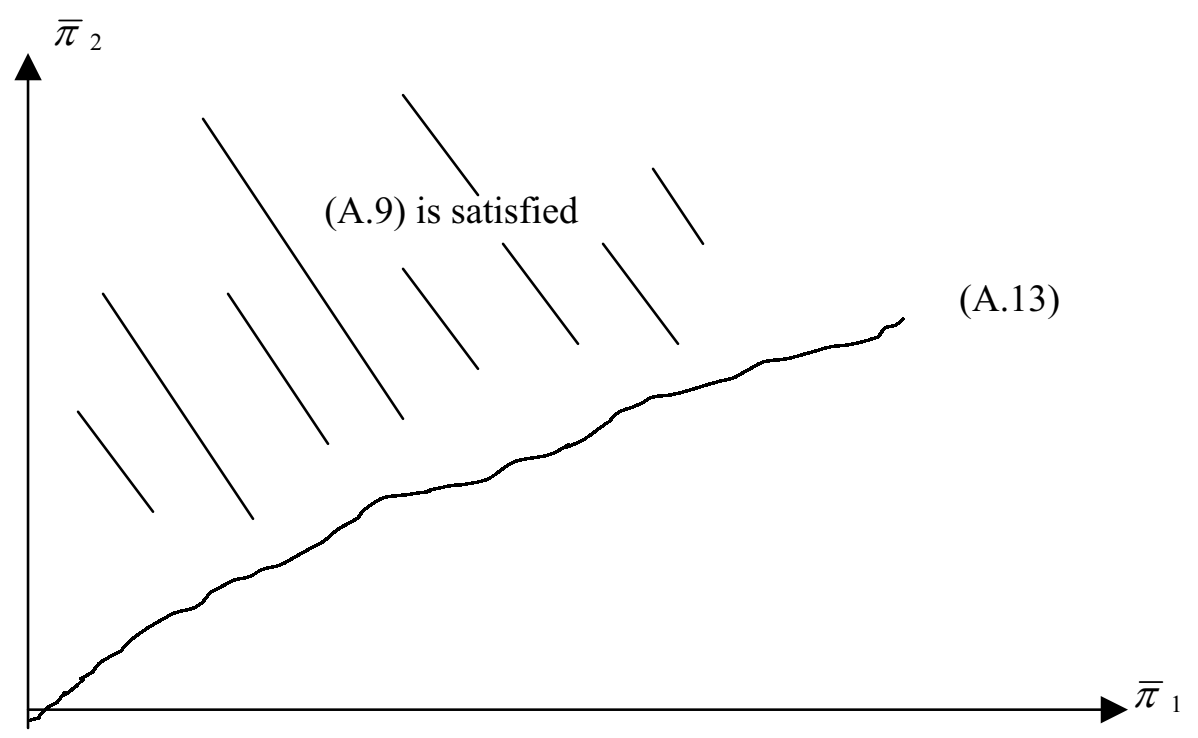

